\title{
SANS Study of the Effects of Water Vapor Sorption on the Nanoscale Structure of Perfluorinated Sulfonic Acid (NAFION) Membranes
}

\author{
Man-Ho Kim, ${ }^{*},+\star$ Charles J. Glinka, ${ }^{\dagger}$ Stephen A. Grot, ${ }^{\S}$ and Walther G. Grot ${ }^{\S}$ \\ NIST Center for Neutron Research, National Institute of Standards and Technology, \\ Gaithersburg, Maryland 20899-8562; Department of Materials Science and Engineering, University of \\ Maryland, College Park, Maryland 20742-2115; and Ion Power, Inc., 720 Governor Lea Rd., \\ New Castle, Delaware 19720
}

Received March 14, 2006; Revised Manuscript Received April 21, 2006

\begin{abstract}
Several poly(perfluorosulfonic acid) membranes (NAFION, EW = 1100) with the same sulfonic acid content were systematically investigated with SANS under in-situ water vapor sorption and/or with bulk water to quantify the effects of relative humidity $(\mathrm{RH})$, membrane processing (melt-extruded and solution-casting), prehistory (pretreated at $80^{\circ} \mathrm{C}$ and as-received), and thickness on the nanoscale structure at room temperature. The sorption isotherm (water uptake vs $\mathrm{RH}$ ) of the membranes showed a strong correlation between the interionic domain distance $\left(L_{\mathrm{ion}}\right)$ and RH. The melt-extruded membranes showed evidence of partial alignment of better organized ionic domains than those solution-cast. Pretreating the membranes resulted in a larger $L_{\text {ion }}$ and a broader scattering over the entire range of $\mathrm{RH}$. The ionic peak of the melt-extruded membranes (as-received and pretreated) became more symmetric and narrower with sorption time. Diffusion coefficients of water vapor, based on structural evolution and Fick's second law, are in the range of $1 \times 10^{-7}-3 \times 10^{-7} \mathrm{~cm}^{2} / \mathrm{s}$ for both extruded (pretreated and as-received) membranes. A thickness-dependent crystalline feature around $Q \approx 0.03 \AA^{-1}$ was also observed.
\end{abstract}

\section{Introduction}

Recently, solid-state fuel cell membranes have been much studied due to their promise as a new environmentally friendly power source for laptop computers, cell phones, motors, and internal combustion engines for automobiles. One of these membranes is the perfluorinated sulfonic ionomer membrane, NAFION (DuPont trade name), ${ }^{65,66}$ which has the properties of thermal stability, chemical inertness, and high proton conductivity. NAFION membranes have become standard-like materials in the field of fuel cell membranes. The properties and performance of newly developed fuel cell membranes are typically compared with those of NAFION. Therefore, the study of this type of material is important.

NAFION membranes of acid form (perfluororosulfonic acid polymer, PFSA) have been considered as future fuel cell membranes for operated at low temperature (around $70-80{ }^{\circ} \mathrm{C}$ ) and relative humidity around $70 \% \mathrm{RH}$. PFSA is manufactured by converting the sulfonyl fluoride $\left(\mathrm{SO}_{2} \mathrm{~F}\right)$ terminal group in a copolymer precursor of tetrafluoroethylene (TFE) and vinyl sulfonyl fluoride to sulfonic acid $\left(\mathrm{SO}_{3} \mathrm{H}\right)$ group. ${ }^{1}$

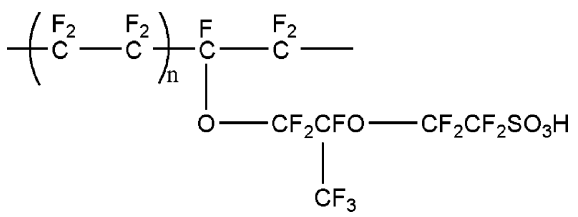

While this structure is fully defined by the average distance between side chains (or TFE/side chain mole ratio), $n$, it is traditionally referred to by $\mathrm{EW}(\mathrm{g} / \mathrm{mol})$, defined as the backbone

* To whom correspondence should be addressed. E-mail: manho.kim@nist.gov.

NIST Center for Neutron Research.

University of Maryland, College Park.

$\S$ Ion Power, Inc. monomer (TFE or $\left.\mathrm{CF}_{2} \mathrm{CF}_{2}\right)$ molar mass $(=100 \mathrm{~g} / \mathrm{mol})$ times $n$, plus the side chain (perfluoro vinyl ether, $\mathrm{C}_{7} \mathrm{~F}_{13} \mathrm{O}_{5} \mathrm{SH}$ ) molar mass $(=444 \mathrm{~g} / \mathrm{mol})$. Thus, for example, an $n$ of 6.6 yields an $\mathrm{EW}(=100 n+444)=1100$. The membrane then consists of this hydrophobic backbone and perfluoro vinyl ether pendant groups with hydrophilic sulfonic acid groups at the terminal of the pendant chain which segregate into microdomains. The larger the EW, the fewer the sulfonic acid groups in the membrane.

Many studies of NAFION membranes have been published. For example, studies of PFSA membranes have focused on the effect of temperature, ${ }^{2-4}$ membrane thickness, ${ }^{5,6}$ water content, and relative humidity $(\mathrm{RH})$ on proton conductivity. The results showed high conductivity at a temperature of $\sim 70{ }^{\circ} \mathrm{C}$, high humidity, and thin membranes (for example, 178-51 $\mu \mathrm{m}$ ). The diffusion coefficient of water was measured for bulk water and for water vapor using a gravimetric method, ${ }^{7-10}$ by tracing the far-infrared (FIR) spectra of the water isotope (HDO), ${ }^{11}$ and by the pulsed-gradient spin-echo NMR method ${ }^{12}$ since the flow of protons from the anode to the cathode is expected to be related to the sorption/diffusion behavior of water molecules. Numerous studies to reveal the structure of the membranes, including the structure under mechanical stress, using smallangle scattering have suggested various kinds of structures like lamellae, core-shell, sphere, cylinder, fibrils, etc. ${ }^{13-17}$ Surface (or near surface) images have been obtained with atomic force microscopy (AFM). ${ }^{18,19}$ Water dynamics in the PFSA membrane have been studied with quasielastic neutron scattering (QENS). ${ }^{20}$ Infrared spectroscopy for studying the water and ionic domain interaction $^{2,21-24}$ and nuclear magnetic resonance (NMR) for studying nuclear dipole-dipole relaxation or chemical structure analysis ${ }^{25-27}$ have also been used. In parallel with experiments, simulations of structure reconstruction from $\mathrm{SAXS},{ }^{28}$ the chain conformation in a solvent, ${ }^{29}$ the effect of the polar side chain distribution on the backbone, ${ }^{30}$ and the aggregation of the ionic domains with water ${ }^{31}$ have been performed. To improve the mechanical properties and high-temperature conductivity, modi- 
Table 1. PFSA Membranes, Thickness of Single Layer, and Sorption Environments

\begin{tabular}{llcc}
\hline \multicolumn{1}{c}{ membrane } & code $^{a}$ & ${\text { thickness (partially dried) }(\mu \mathrm{m})^{b}}^{b}$ & SANS experiment environment \\
\hline melt-extruded (as-received) & Ex112asr & $48-51$ & vapor, liquid water \\
melt-extruded (pretreated) & Ex112cln & $48-51$ & vapor, liquid water \\
solution-cast (as-received) & Cs112asr & $36-41$ & liquid water \\
melt-extruded (as-received) & Ex117asr & 183 & liquid water \\
& Ex1110asr & 254 & liquid water \\
& none & $25,89,127$, and 254 & liquid water
\end{tabular}

${ }^{a}$ Ex, Cs, asr, and cln stand for melt-extruded, solution-cast, as-received, and pretreated (or cleaned), respectively. ${ }^{b}$ The sample thickness $(\mu \mathrm{m})$ is the mean value of measurements at several points across a single film (as-received). The thicknesses, 25, 48-51 (Ex112asr and Ex112cln), 89, 127, 183 (Ex117asr), and $254 \mu \mathrm{m}$ (Ex1110asr) of the melt-extruded membranes correspond to N111, N112, N1135, N115, N117, and N1110 in the manufacture symbol. In both our nomenclature and that of the manufacturer, the first two digits, 11, represent EW $=1100$ and the remaining digits the thickness in thousandths an inch (mil) of membranes.

fications or composites of PFSA membranes have been made. ${ }^{32-36}$ Recently, review articles on this membrane have appeared in the literature. ${ }^{37-39}$

The PFSA membranes are manufactured in various thicknesses and sulfonic acid content by melt-extrusion or solutioncasting. The membranes can be used as-received or after pretreatment. In addition, as mentioned in the literature cited above, the proton conductivity of NAFION membranes depends on relative humidity, diffusion coefficient, water uptake, and temperature. Therefore, correlating the water vapor sorption/ diffusion with the structural changes is important to understand the proton conductivity, sorption behavior, and the mechanical and physical properties of the membranes. The first purpose of this study is to understand the effect of the membrane processing method (i.e., melt-extrusion and solution-cast), thickness, and prehistory (as-received and pretreated) on the nanoscale features such as the interionic domain distance $\left(L_{\mathrm{ion}}\right)$ and interlamellar (or fringed micelle) of the crystalline phase $\left(L_{\mathrm{c}}\right)$ with the membrane wet in bulk water. A second aim is to obtain simultaneously the diffusion coefficient of water vapor (not liquid water), water content, sorption kinetics, and nanostructural parameters $\left(L_{\text {ion }}\right.$ and $\left.L_{\mathrm{c}}\right)$ in as-received and pretreated thin membranes (thickness $\approx 50 \mu \mathrm{m}$ ) by monitoring the nanoscale structure in real time during water vapor sorption at constant RH. Finally, a third objective is to find a correlation between the water sorption and structural changes. For the second and third purposes, in-situ vapor sorption SANS (iVSANS) measurements ${ }^{40,41}$ were performed.

This paper consists of the following sections: (i) a brief description of the pretreatment of the membranes and the iVSANS experiment, (ii) the results of measurements on several as-received membranes wet with bulk water, which demonstrate the effect of membrane thickness and manufacturing process, (iii) the structural evolution with water vapor sorption and the correlation between the $L_{\text {ion }}$ (interionic domain distance) and the fractional volume gain of water, and (iv) the determination of the diffusion coefficient from the iVSANS signal.

\section{Experimental Section}

Sample Pretreatment. Melt-extruded NAFION 112 membranes (50 $\mu \mathrm{m}$ thickness, $\mathrm{EW}=1100)$ of the acid form were obtained from Ion Power Inc. The extrusion is done in the precursor $\left(-\mathrm{SO}_{2} \mathrm{~F}\right)$ form at about $280{ }^{\circ} \mathrm{C}$. There is some draw as the film exits the die. The film then goes over a chrome-plated chill roll. The fabricated precursor film is then hydrolyzed to the salt $\left(\mathrm{K}^{+}\right.$or $\left.\mathrm{Na}^{+}\right)$form by treating with hot $10 \% \mathrm{KOH}$ (or $\mathrm{NaOH}$ ) solution (optionally plus about $20 \%$ dimethyl sulfoxide, DMSO) at $80-90{ }^{\circ} \mathrm{C}$. This reaction may take about an hour, depending on thickness. The completion of this conversion was determined by infrared spectroscopy (disappearance of $-\mathrm{SO}_{2} \mathrm{~F}$ peak). The film of the salt form was converted to the acid $\left(\mathrm{H}^{+}\right)$form using the $10 \%$ nitric acid at room temperature. This reaction took only a few minutes. ${ }^{42}$ Solutioncast membranes were prepared by drying PFSA resins dissolved in a mixture of water ( 15 wt $\%$ ) and alcohols at $50{ }^{\circ} \mathrm{C}$ for $1 / 2 \mathrm{~h}$, followed by a curing step at $100-120^{\circ} \mathrm{C}$ for $15 \mathrm{~min} .{ }^{43}$ All of the processing steps described here were carried out (at the manufacturer) prior to sending the films to NIST for the SANS measurements.

The membranes were pretreated as follows: as-received membranes showing a pale brown color were placed in $3 \mathrm{vol} \%$ of $\mathrm{H}_{2} \mathrm{O}_{2}$ at $80 \pm 1^{\circ} \mathrm{C}$ for $2 \mathrm{~h}$ to remove organic contaminants. At this stage, the light brown color disappeared. The clear membranes were rinsed in deionized water at $23{ }^{\circ} \mathrm{C}$ several times to remove $\mathrm{H}_{2} \mathrm{O}_{2}$. Subsequently, the membranes were immersed in $0.5 \mathrm{M} \mathrm{H}_{2} \mathrm{SO}_{4}$ at $80 \pm 1{ }^{\circ} \mathrm{C}$ for $2 \mathrm{~h}$ to replace any foreign cations with protons, followed by rinsing in deionized water several times to remove $\mathrm{H}_{2} \mathrm{SO}_{4}$. Although the pretreatment was performed in boiling dilute $\mathrm{H}_{2} \mathrm{SO}_{4}$ and $\mathrm{H}_{2} \mathrm{O}_{2}$ solution in a previous study, ${ }^{44} 80 \pm 1{ }^{\circ} \mathrm{C}$ was chosen here to minimize any possible reorganization of structure in boiling water solution. The pretreated membranes were dried in a vacuum oven with a desiccant at RT for 1 day and then at $40 \pm$ $1{ }^{\circ} \mathrm{C}$ for several hours until their weight became constant. This procedure removes most, but not all, water molecules from the membrane. According to our IR results, it takes several days under vacuum at RT to remove the water molecules completely, even with a $25 \mu \mathrm{m}$ thick sample. Deionized water was used for the measurements. Table 1 is a summary of the samples and experiment environment.

In-Situ Vapor Sorption SANS (iVSANS). The predried extruded membranes (six layers of Ex112cln or Ex112asr membranes) were loaded into the iVSANS cell with their machine (i.e., extrusion) direction (MD) and transverse direction (TD) aligned with each other. The individual layers were held in place at their edges by spacer rings. The membranes were thus effectively freestanding over the central area (diameter $\approx 1.27 \mathrm{~cm}$ ) exposed to the neutron beam.

The cell with the membranes and vapor delivery lines was evacuated before the saturated vapor was introduced. The relative humidity in the iVSANS cell was actively controlled by monitoring the absolute water vapor pressure in the cell and feeding or removing vapor whenever the pressure in the cell deviated from the target vapor pressure. Vapor was generated from the degassed water in the bubbler. Details on the apparatus, principles of operations, and apparatus performance are described elsewhere. ${ }^{41}$ The membranes were equilibrated at $2.0 \% \mathrm{RH}$ and then further dried at $\sim 0 \pm 67 \mathrm{~Pa}(0.00 \pm 0.50$ Torr $)$ at room temperature until the total detector counts of SANS become constant for $\sim 30 \mathrm{~min}$ to ensure that the membrane condition (i.e., amount of residual water in the membrane) was the same at the start of each measurement. After drying, the humidity in the cell was raised to a target RH. SANS data collection was immediately started once the target $\mathrm{RH}$ was reached, except for $\mathrm{RH}$ of $95 \%$. In this case, the SANS measurement was started when $\mathrm{RH}$ reached 0.9 of the $95 \%$ target $\mathrm{RH}$ (i.e., at $\mathrm{RH} \approx 85 \%)$ due to the long response time $(\sim 10 \mathrm{~min})$ to reach that target RH. Stability and response time will be shown in the diffusion section. SANS measurements were performed in the range of $Q\left(=\{4 \pi \sin (\theta)\} / \lambda_{\mathrm{n}}\right.$, where $2 \theta$ and $\lambda_{\mathrm{n}}$ are the scattering angle and neutron wavelength, respectively) from 0.01 to $0.3 \AA^{-1}$ using the $30 \mathrm{~m}$ SANS instruments (NG3 and NG7) at the NISTCNR (neutron wavelength $\lambda_{\mathrm{n}}=5.5 \AA, \Delta \lambda_{\mathrm{n}} / \lambda_{\mathrm{n}}=15 \%$, sample-to- 


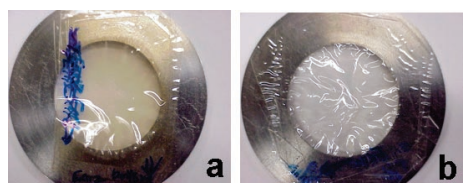

Figure 1. As-received (EX112asr) (a) and pretreated (Ex112cln) (b) membranes after iVSANS measurement. There were no wrinkles on loading the membranes in the cell. The wrinkles were generated during water vapor sorption. Blue marks on the membranes, which were used for indicating the machine direction, were out of the SANS beam.

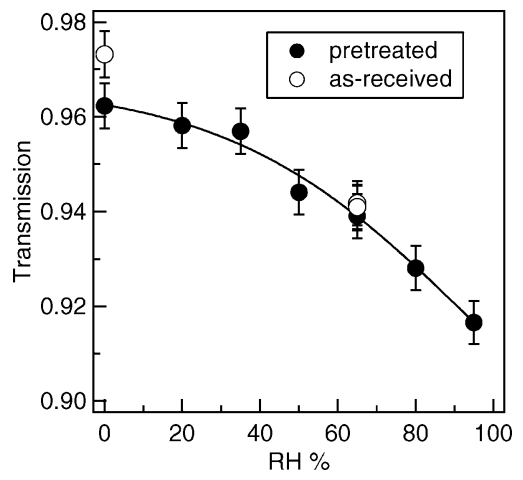

Figure 2. Neutron transmission of the pretreated (Ex112cln) and asreceived (Ex112asr) membranes equilibrated at each RH (\%). At 65\%, transmission was measured twice to check reproducibility by reloading and reconditioning the pretreated membranes.

detector distance $(\mathrm{SDD})=1.878 \mathrm{~m}$ for iVSANS measurement using NG3, and $\lambda_{\mathrm{n}}=8.09 \AA, \Delta \lambda_{\mathrm{n}} / \lambda_{\mathrm{n}}=10 \%, \mathrm{SDD}=15.3 \mathrm{~m}$ and $\lambda_{\mathrm{n}}=$ $6 \AA, \Delta \lambda_{\mathrm{n}} / \lambda_{\mathrm{n}}=10 \%, \mathrm{SDD}=4.5$ and $1.1 \mathrm{~m}$ for the membrane wet with bulk water using NG7). ${ }^{45}$ The accuracy of the scattering vector calibration was confirmed at SDD $=1.878 \mathrm{~m}$ with the first reflection $\left(Q(001)=0.1075 \AA^{-1}\right)^{46}$ of silver behenate $\left(\mathrm{CH}_{3}\left(\mathrm{CH}_{2}\right)_{20^{-}}\right.$ COOAg).

The physical appearance and color of the as-received and the pretreated membranes, partially dried after the iVSANS measurement, are shown in Figure 1.

The color of both membranes did not change during the measurement, confirming there was no indication of further degradation (or organic contamination). The smooth surface of the initial dry membrane, however, became creased by the swelling process during water vapor sorption because the circular edge of the stacked membrane layers was fixed. It was assumed that the macroscale wrinkles did not affect the SANS scattering, which probes structure on the nanometer scale.

The SANS and ultrahigh-resolution small-angle neutron scattering (USANS) measurements of the as-received PFSA membranes $(E W=1100)$ with several different thickness from 25 to $254 \mu \mathrm{m}$, wetted in bulk deionized water, were also measured by placing each wet membrane between two quartz windows. No wrinkles in this case were observed. The USANS measurement was performed using a Bonse-Hart-type instrument (at BT5 of NCNR) that uses a pair of triple-bounce channel-cut perfect silicon (220) crystals as monochromator and analyzer, and $\lambda_{\mathrm{n}}=2.4 \AA{ }^{47}$

Neutron Transmission Measurement. Neutron transmission of the pretreated membranes decreases by about $5 \%$ in a semiparabolic manner from the $\sim 96 \%$ for the dry to $\sim 92 \%$ for the membrane equilibrated at $95 \%$ RH (Figure 2).

The transmission of the as-received and pretreated membrane is about $0.97-0.96$ with a $\lambda_{\mathrm{n}}=5.5 \AA$. The neutron transmission used to normalize the SANS data taken at each RH was the transmission measured at the equilibrium of each $\mathrm{RH}(\%)$ for convenience. Repeated measurement of transmission at $65 \% \mathrm{RH}$ by reloading and reconditioning the pretreated membrane showed good reproducibility as seen in Figure 2.

Cross Section. Depending on the information required from the iVSANS measurements, relative intensity (total counts) or total cross section (i.e., absolute intensity, $\mathrm{cm}^{-1}$ ) was used. The constant sample thickness of the dry membranes was used for total cross-

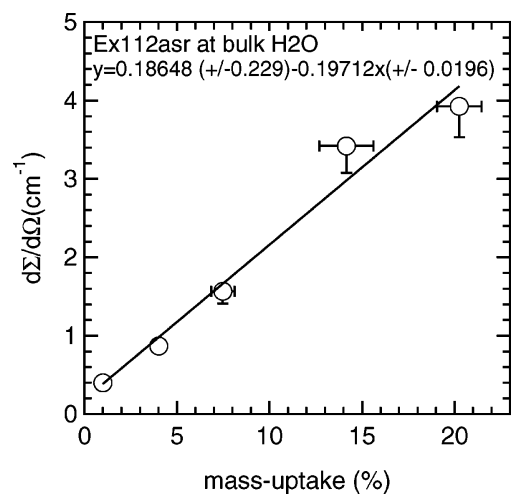

Figure 3. Plot of the differential cross section at the ionic peak position vs percentage increase in sample mass due to water uptake. These data are used (for Figure 9) to infer water uptake from the iVSANS measurements on other samples. Vertical error bars indicate uncertainty in the sample thickness for higher percentage of mass uptake.

section calibration despite the increase of thickness by swelling during sorption. Thus, strictly speaking, the total cross section corrected with a constant thickness of the dry sample is a pseudoextensive property. Assuming mass uptake is proportional to the sample thickness, the uncertainty in the total cross section could be as large as $10 \%$ for the as-received and $17 \%$ for the pretreated samples since the pretreated samples take up more water vapor. The water uptake during the iVSANS measurements was determined using the calibration plot, Figure 3, which shows that there is a linear relationship between the cross section at the ionic peak and mass uptake of the as-received membranes. The water uptake given in the calibration plot was determined gravimetrically for one as-received sample.

Water Content. The water content in the membrane is usually defined as a number $\lambda$ of water molecules per sulfonic acid site, $\lambda$ $=n_{\mathrm{H}_{2} \mathrm{O}} / n_{\mathrm{SO}_{3} \mathrm{H}}\left(n_{i}\right.$ is the number of moles for each species). The $\lambda$ can be expressed in terms of equivalent weight (EW) and mass change during water vapor sorption:

$$
\lambda=w \mathrm{EW} / 18
$$

where $w\left(=\left(m_{\text {wet }}-m_{\text {dry }}\right) / m_{\text {dry }}\right)$ is the mass uptake gain and 18 is the molar mass $(\mathrm{g} / \mathrm{mol})$ of water. Mass gain $w$ can be converted to fractional volume gain $\phi_{\mathrm{v}}$ as follows: $\phi_{\mathrm{v}}=\left(\rho_{\text {dry }} / \rho_{\mathrm{H}_{2} \mathrm{O}}\right) w$ (see Appendix $)$, where $\rho_{\text {dry }} \approx 2.0 \mathrm{~g} / \mathrm{cm}^{3}{ }^{14}$ and $\rho_{\mathrm{H}_{2} \mathrm{O}}=1.0 \mathrm{~g} / \mathrm{cm}^{3}$ are the densities of the dry membrane for EW1100 and water, respectively.

\section{Results and Discussion}

Structure of Membranes Wet with Bulk Water. PFSA membranes are usually manufactured in two ways: melt extrusion and solution-casting. The structures of the membranes are expected to depend on the processing method, membrane thickness, and thermal history, etc., as well as water content. Figure 4 shows SANS two-dimensional patterns and corresponding circularly averaged profiles illustrating the effects of sample thickness and processing on the structures.

The solid membranes were wet in bulk water to study the effects of sorption on structure. To better isolate the effects of the membrane processing on the structure, samples with similar mass uptake were compared. Several characteristic features representing orientation, crystallization, and ionic domain organization in the membranes can be seen in both the 2D pattern (Figure 4a, top) and the circularly averaged profiles (Figure 4b, bottom).

In Figure 4a, the melt-extruded membranes (Ex112asr and Ex117asr) show an anisotropic scattering pattern in the outer scattering ring that corresponds to the interionic domain peak while the solution cast membranes (Cs112asr) show an isotropic pattern. The inner region of the Ex117asr shows strong 

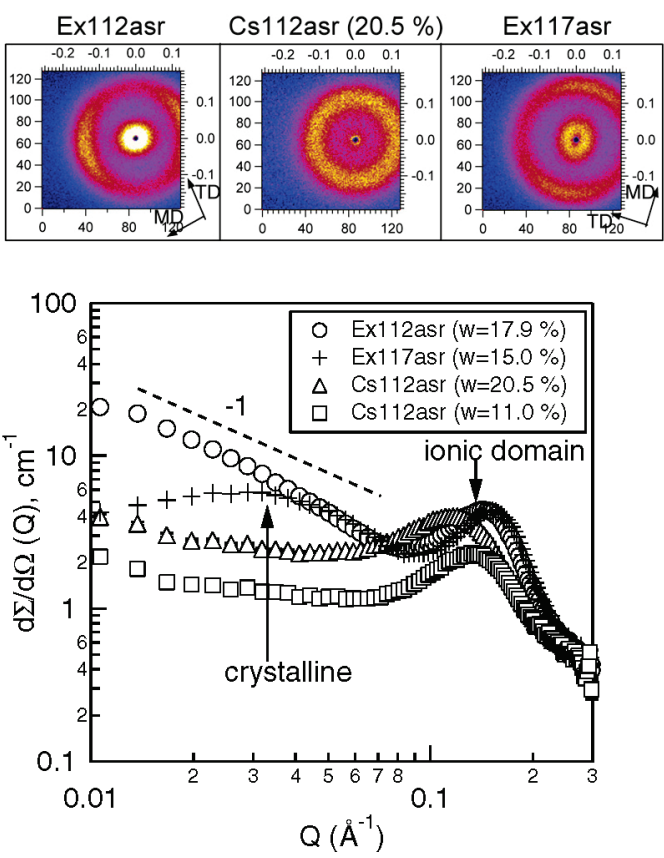

Figure 4. (top, a) SANS 2D pattern of extruded Ex112asr, Ex117asr, and Cs112asr $(w=20.5 \%)$ membranes wet with $\mathrm{H}_{2} \mathrm{O}$. (bottom, b) Corresponding circularly averaged scattering profiles with the indicated mass uptake $(w)$.

Table 2. Structural Parameters (Interionic Domain Distance, $L_{\mathrm{ion}}$, and Full Width at Half-Maximum, fwhm) and Water Mass Uptake (\%) of the PFSA Membranes from Figure 4

\begin{tabular}{cccc}
\hline sample & $L_{\text {ion }}(\AA)$ & fwhm $(\AA)$ & $w(\%)$ mass gain \\
\hline Ex112asr & 45.0 & $0.0950 \pm 0.003$ & 18 \\
Ex117asr & 42.6 & $0.0873 \pm 0.005$ & 15 \\
Cs112asr & 56.0 & $0.1061 \pm 0.003$ & 21 \\
Cs112asr & 48.0 & $0.1022 \pm 0.001$ & 11
\end{tabular}

anisotropic scattering, whereas the Ex112asr and Cs112asr show weak and no orientation scattering, respectively. Figure 4a demonstrates that melt extrusion causes orientation of ionic group domains and produces larger scale structure corresponding to the scattering in the low $Q$ region $\left(Q<0.1 \AA^{-1}\right)$. The corresponding plot of circularly averaged intensity vs scattering vector (Figure $4 \mathrm{~b}$ ) shows other characteristic features. The ionic peak, $Q_{\text {ion }} \approx 0.150 \AA^{-1}$ (which depends on the amount of water in the membrane), of Ex112asr with $w=18 \%$ appears at higher $Q$ than that, $Q_{\text {ion }} \approx 0.117 \AA^{-1}$, of Cs112asr with $w=11 \%$. Furthermore, the peak width of the extruded sample is narrower than that of the cast membrane (Table 2) despite (i) the former having greater water content and (ii) both membranes having the same amount of sulfonic acid groups and similar thicknesses.

Usually, the ionic peak shifts to lower $Q$ as the amount of water in the ionic domain increases due to expansion of the distance between ionic domains. However, the peak of Ex112asr $(w=18 \%)$ appears at higher $Q$ than that of Cs112 $(w=11 \%)$ even though the water content in Ex112asr is higher than Cs112asr. The interionic domain spacing $\left(L_{\text {ion }}\left(=2 \pi / Q_{\text {ion }}\right)=\right.$ $45 \pm 1 \AA$ at $w=18 \%)$ of Ex112asr is smaller than that $\left(L_{\text {ion }}=\right.$ 56 and $48 \AA$ at $w=20.5 \%$ and $11.0 \%$, respectively) of the cast membranes. Figure 4 demonstrates that the membrane processing/preparation conditions do affect the structure. The structure of the melt-extruded membrane is better arranged as indicated by sharper peak than the solution-cast membrane although the exact morphology is not known. Since the structure of the cast membrane is believed to depend on the solution composition ${ }^{48,49}$ as well as drying and curing temperature, a structure that is significantly different from melt-extruded samples may also be
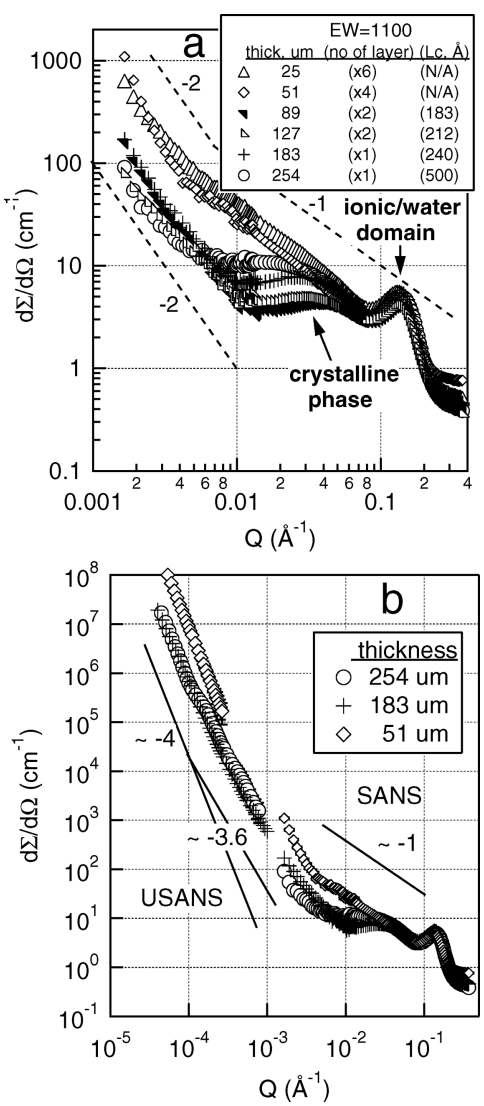

Figure 5. (a) SANS profiles of the extruded membranes (as-received, EW1100) with different sample thickness. The membranes were soaked in bulk water for around $20 \mathrm{~min}$. The SANS measurements were done with multiple layers indicated in parentheses. The corresponding crystalline long spacing $\left(L_{\mathrm{c}}\right)$ is also shown. (b) Desmeared USANS profiles of some selective membranes $(254,183$, and $51 \mu \mathrm{m}$ for Ex1110asr, EX117asr, and Ex112asr) together with corresponding SANS profiles. The gap between USANS and SANS is because the USANS was too weak to measure above $Q=0.001 \AA^{-1}$ as needed to overlap the range of the SANS measurements. The dotted (a) and solid (b) lines are guides for the eye.

possible. A shorter interionic domain distance in Ex112asr than that of the cast membrane may be due to alignment of ionic domain and matrix (backbone chain), resulting in shrinkage along the transverse direction and extension along the extrusion direction.

A difference in the presence of a crystalline phase among the membranes is also clearly shown in Figure 4b. Ex117asr shows a broad crystalline peak at around $Q_{\mathrm{c}} \approx 0.03 \AA^{-1}$ due to the stress-induced and/or nonisothermal crystallization during cooling from the melt while the thin Ex112asr does not clearly show the feature, demonstrating that crystallization from the melt is affected by membrane thickness, as expected. Also, there is no indication of crystallization in the Cs112asr. The effect of membrane thickness on the crystalline feature is further confirmed in Figure 5a for the melt-extruded membranes of EW $=1100$.

The crystalline peak $\left(Q_{\mathrm{c}} \approx 0.03 \AA^{-1}\right)$, which has been inferred in earlier studies, ${ }^{13,14}$ becomes more prominent and shifts to a lower $Q$ as the membrane thickness increases from 89 to 254 $\mu \mathrm{m}$ and the corresponding long spacing $L_{\mathrm{c}}\left(=2 \pi / Q_{\mathrm{c}}\right)$, distance between crystalline regions, of the crystalline phase increases from 183 to $500 \AA$. Again, the thin membranes, below $50 \mu \mathrm{m}$, do not show a clear crystalline feature. The position of the ionic peak is almost constant regardless of sample thickness. The effect of thickness on the crystalline peak can be explained as follows: Thick membranes (precusor form) take more time to 
cool from the melt so that thick membranes stay at a crystallization temperature $\left(T_{\mathrm{c}}\right)$ longer than thin samples as well as taking a longer reaction time to convert the precusor to the salt form at $80-90{ }^{\circ} \mathrm{C}$, which is a favorable condition for crystallization. The peak position and its breadth represent the most probable $L_{\mathrm{c}}$ and crystallite thickness distribution, respectively, both of which depend on thermal history.

The SANS patterns for the extruded samples in Figure 5a show marked differences for $Q$ values below the position of the interionic domain peak $\left(Q_{\text {ion }}<0.1 \AA^{-1}\right)$. The thinnest samples show an extended power law behavior, with a slope of approximately -1 , before rising with a steeper slope at the lowest $Q$ values $\left(Q<0.005 \AA^{-1}\right)$. A slope of -1 is characteristic of rodlike structures and suggests that the ionic domains may form extended, fringed micelles like those depicted in Figure 6b. The formation of such micellar domains appears to be a direct consequence of the extrusion process since we do not observe a -1 slope for thin solution-cast membranes of the same material (see Figure 4). In contrast to our results, Rubatat et al. ${ }^{50}$ observed a slope of close to -1 in the $Q$ range of $Q=$ 0.006-0.08 $\AA^{-1}$, and no crystalline peak, for some thick neutralized swollen NAFION membranes, Li7-N117 (thickness $\sim 175 \mu \mathrm{m})$. Their samples might be swollen with water at high temperature and high pressure in an autoclave (the temperature and pressure are not reported by the authors), which may have destroyed the crystalline phase. The steep rise in the scattering from the thicker samples for $Q<0.01 \AA^{-1}$ extends to very low $q$ region below $Q=0.001 \AA^{-1}$ for both thick $(183 \mu \mathrm{m}$ Ex117asr and $254 \mu \mathrm{m}$ Ex1110asr) and thin membrane $(51 \mu \mathrm{m}$ Ex112asr) (see Figure 5b) according to our USANS measurements. The very low angle scattering of the semicrystalline membrane likely originates from clustering of the crystalline regions, forming larger scale structure like spherulite, bundled fringed micelles, or stacked lamellae. The USANS data of the thick membrane $(\approx 254 \mu \mathrm{m}$, Ex1110asr) exhibit a power law scattering $\left(\mathrm{d} \Sigma / \mathrm{d} \Omega(Q) \approx Q^{-\alpha}\right.$, where the power law exponent $\alpha$ is defined as $\alpha=6-D_{\mathrm{f}}$ for three-dimensional object ${ }^{51}$ ) in the range of $Q$ from $10^{-3}$ to $10^{-4} \AA^{-1}$, which suggests that a superstructure in the range of approximately $1-10 \mu \mathrm{m}$ is surface-fractal-like structure with a fractal dimension of $D_{\mathrm{f}}=$ 2.4). On the other hand, Ex117asr (thickness: $183 \mu \mathrm{m}$ ) exhibits Porod scattering (i.e., $\alpha=-4$ ) in the entire $Q$ range below $10^{-3} \AA^{-1}$. This indicates that the surface of the largest structures is smooth, while Ex1110asr shows the Porod scattering only below $10^{-4}$. This may suggest that slower cooling rate causes the crystalline surface to roughen due to large variations in the thickness of crystalline phase. Of interest is that the thin membrane (EX112asr, $\sim 50 \mu \mathrm{m}$ thick), which does not show a clear crystalline scattering, also shows Porod scattering. This may originate from larger scale inhomogenieties associated with the ionic domains, but the origin of this scattering is not known.

It is not known whether the morphology of crystalline phase is lamellar-like (A1 in Figure 6a) or fringed-micelle-like (B1, B2, and B3 of Figure 6a). Attempts, including ours, to determine the morphology have not been conclusive.

The structure of the crystalline phase is expected to depend on the distribution of the side chains (perfluorosulfonic acid group or comonomer) along the backbone chain (Figure 6a). The distribution of the side chain along the backbone in NAFION is not clearly known except for the averaged EW. The bulky side chain plays a role as a defect hindering the crystallization and is expected to be rejected from the crystalline phase formed by the linear backbone segments of the chains. ${ }^{54,55}$ For example, if the side chain distribution along the backbone is heterogeneous (an example of the extreme case is shown in Figure $6 \mathrm{a}(\mathrm{A})$ ), the long defect-free backbone chains (TFE) can fold back adjacently or loosely on the crystalline plane, forming the lamellar phase (Figure 6a (A1)). On the other hand, in the case of a random or homogeneous distribution of the side chains for the membrane with $\mathrm{EW}=1100(n \approx 7)$, only short linear chain segments, free of defects (i.e., side chain), exist in the backbone chain (Figure 6a (B)). This makes it energetically difficult for the chains to register and fold back on a growing crystalline face because of a hindrance by bulky side chains (i.e., defects). One possible crystalline structure is a fringed micelle model (B1 and B2) consisting of cylindrical bundles (crystalline phase) of the linear segments (TFE) aligned in parallel, with the bulky side group expelled from the crystalline phase, leading to the slope of -1 , characteristic of long cylinders, in the small-angle scattering profile. A detailed schematic of the possible structure for the amorphous membrane (i.e., thin membrane $<50 \mu \mathrm{m}$ thick) is shown in Figure $6 \mathrm{~b}$. We note that the schematic model depicted in Figure 6, while consistent with our data, is not fully justified by the data and differs in some respects from models proposed in the literature (e.g., by Starkweather ${ }^{56}$ and van der Heijden et al. ${ }^{57}$ )

Structure Evolution of Melt-Extruded Membranes with Water Vapor Sorption. In small-angle scattering, the macroscopic cross section (cross section per unit volume, $\mathrm{cm}^{-1}$ ), $\{\mathrm{d} \Sigma /$ $\mathrm{d} \Omega\}(Q)$, or absolute intensity, for a simple two-phase system is a function of contrast and volume fraction $(\Phi)$ of each phase.

$$
\mathrm{d} \Sigma / \mathrm{d} \Omega(Q) \propto \Phi(1-\Phi)(\Delta \mathrm{SLD})^{2} K(Q)
$$

where $K(Q)$ contains the structure information regarding the shape, the polydispersity, and the orientation of scatterers. The contrast is defined as the squared difference, $(\triangle S L D)^{2}$, of the coherent neutron scattering length densities (SLD) of the phases or domains in the material. The SLD is given by SLD = $\left(\sum_{i}^{n} b_{i}\right) / V$ for neutrons where $b_{i}$ is the bound coherent scattering length of atomic species $i, 1 / V\left(\mathrm{~cm}^{-3}\right)$ is the number density given, for example, by $N_{\mathrm{A}}\left(\rho / M_{\mathrm{W}}\right)$ where $N_{\mathrm{A}}$ is Avogadro's number, $\rho$ is the mass density $\left(\mathrm{g} / \mathrm{cm}^{3}\right)$, and $M_{\mathrm{w}}$ is the molar mass $(\mathrm{g} / \mathrm{mol})$ of a repeating unit of a polymer chain. In PFSA membranes, the dominant contrast is given by $(\triangle \mathrm{SLD})^{2}=$ $\left(\mathrm{SLD}_{\text {membrane }}-\mathrm{SLD}_{\mathrm{H}_{2} \mathrm{O}}\right)^{2}$, where $\operatorname{SLD}_{\text {membrane }}\left(=4.07 \times 10^{-6}\right.$ $\AA^{-2}$ with $\left.\rho \approx 2.0 \mathrm{~g} / \mathrm{cm}^{3}{ }^{12}\right)$ and $\operatorname{SLD}_{\mathrm{H}_{2} \mathrm{O}}\left(-5.6 \times 10^{-7} \AA^{-2}\right.$ with $\rho=1.0 \mathrm{~g} / \mathrm{cm}^{3}$ ) are the SLD's of PFSA, including the sulfonic acid group, and of bulk water, respectively.

Figure 7 shows an example of the structure evolution in the pretreated Ex112cln with sorption time at 95\% RH, where RH was controlled by controlling absolute pressure in the sorption cell. The scattering profiles measured at other $\mathrm{RH}$ showed similar behavior including those for Ex112asr. Similar profiles were reported for the as-received Ex112asr in ref 41 using flowing nitrogen gas saturated with water vapor.

The cross-section growth demonstrates that water molecules are mainly accumulated in the microphase-separated hydrophilic ionic domain without penetrating the hydrophobic fluorocarbon matrix. If water penetrated the matrix to the same degree, the contrast and hence the scattered intensity would decrease (eq 2). Furthermore, the fact that the scattering intensity increases with sorption time by roughly the same factor over the entire $Q$ range suggests that a two-phase model is an appropriate model.

The accumulation of water molecules with sorption time is also indicated by a shifting of the ionic domain peak (around $Q_{\text {ion }} \approx 0.19-0.2 \AA^{-1}$ ) of the dry sample toward lower $Q$. This 
a
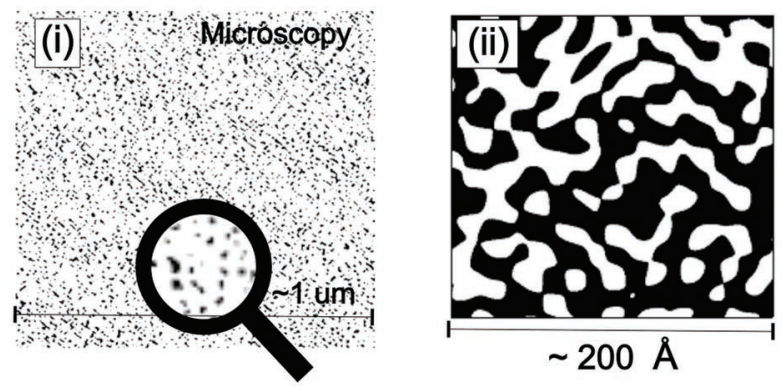

$\sim 200 \AA$
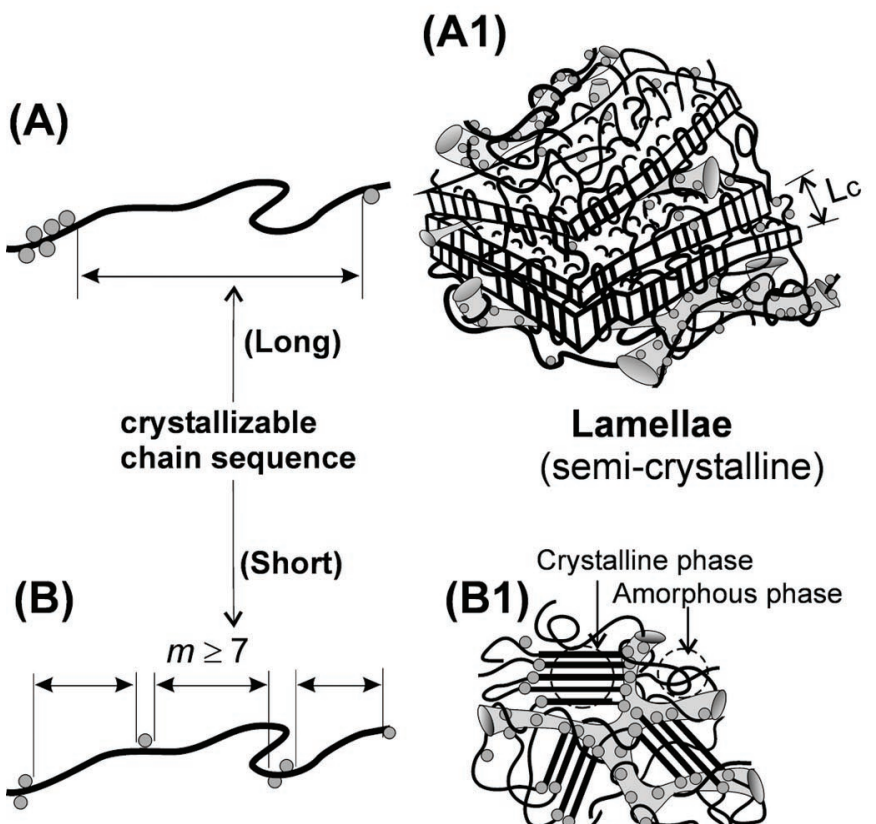

crystallizable chain sequence

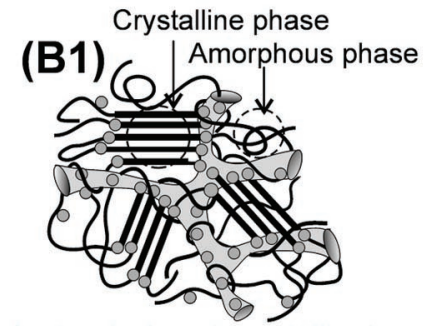

Isotropic (semi-crystalline)

(B2)

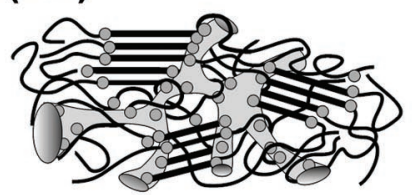

Oriented (semi-crystalline)
(B3)

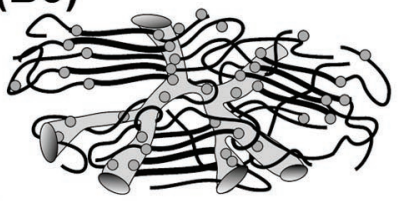

Oriented (Non-crystalline)

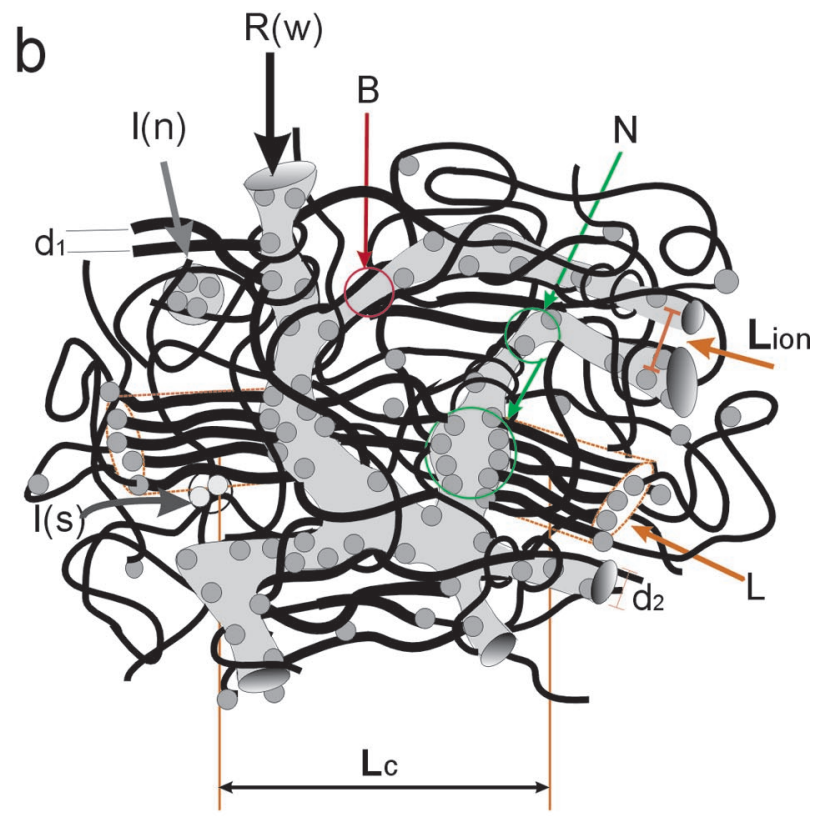

d1: Inter chain distance (approximately, $4 \sim 20 \AA$ depending on the size and location of side chain)

L: Locally packed defect-free chain bundles (crystallizable and locally cylindrical in shape)

Lc: Long period upon crystallization in a fringedmicelle shape (>100 $\AA$ ) (amorphous membranes do not have this feature)

$\mathrm{L}_{\text {ion: }}$ : Inter ionic domain distance $(\sim 30 \AA)$ depending on water (or solvent) content

d2: Diameter of cylindrical channel $\left(<L_{\text {ion }}\right)$

I(n): Isolated ionic domain (no water flows)

I(s): Isolated $\mathrm{SO}_{2} \mathrm{~F}$ or salt domain (no water flows)

$\mathrm{R}(\mathrm{w})$ : Randomly interconnected cylindrical ionic domain (water flow channel)

B: Backbone chain (hydrophobic) wall

$\mathrm{N}$ : Nonuniform aggregation of sulfonic acids group

\title{
Fringed micelle
}

\author{
Side chain $-\left(\mathrm{OCF}_{2} \mathrm{CF}\left(\mathrm{CF}_{3}\right) \mathrm{OC}_{2} \mathrm{~F}_{4} \mathrm{SO}_{3} \mathrm{H}\right)$ \\ or sulfonic acid group $-\mathrm{SO}_{3} \mathrm{H}$ \\ (Non-crystallizable defect) \\ $\approx$ Backbone chain $-\left(\mathrm{CF}_{2} \mathrm{CF}_{2}\right)_{\mathrm{m}}\left(\mathrm{CFCF}_{2}\right)-$
}

Figure 6. (a) Schematics of possible structure of the melt-extruded PFSA membrane in the region of microscale (i and ii) and nanometer (1-100 $\mathrm{nm}, \mathrm{A}$ and B) scale. Microscopy images, (i) and (ii), were simulated with a random field distribution function. ${ }^{52,53}$ Gierke et al. ${ }^{14}$ and McLean et al. ${ }^{18}$ show actual micrograph images similar to (i) and (ii). AFM may not be able to distinguish the amorphous and ionic domains because both domains are soft. Structure on the nanometer scale depends on the distribution of side chains along the backbone and the sample thickness. (A) and (B) show the distribution of extreme cases for the same EW. Upon crystallization, the blocky chain segments (A, long sequence of side chain-free backbone) become lamellae (A1). Structure on this scale should not be related to sample thickness. Chains with a short linear chain sequence may crystallize in a fringed micelle shape (B1 or B2). When the cooling process is fast enough, crystallization does not occur (B3) (e.g., thickness < $50 \mu \mathrm{m}$ ). The superstructure (like spherulite or other possible morphology) formed by clustering of the units of the lamellae or fringed micelles is not shown in these schematics. (b) Detailed schematic representation of a possible PFSA membrane amorphous domain structure in Figure 6 (B3). 


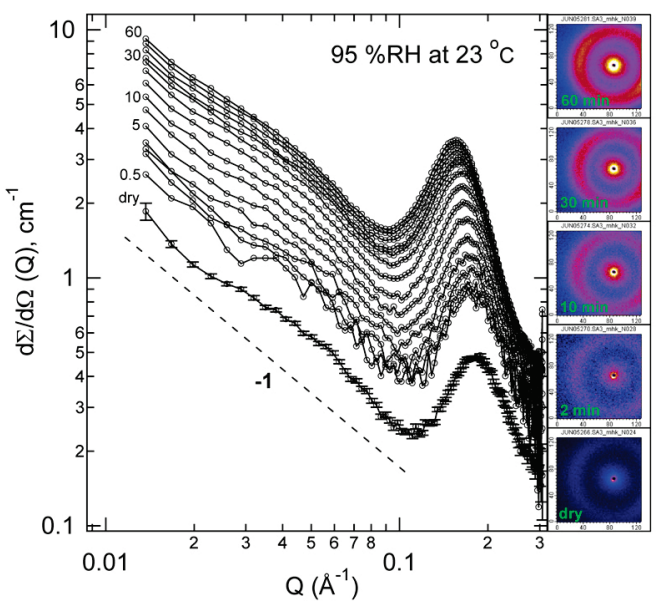

Figure 7. Structure evolution of the pretreated NAFION membrane, EX112cln, with sorption time at 95\% RH. From bottom, sorption time (iVSANS run time) is dry (10), $0.5(0.5), 1$ (0.5), 2 (1), 3 (1), 5 (2), 7 (2), 10 (3), 15 (5), 20 (5), 30 (5), 40 (10), 50 (10), and 60 (10) min. Shown on the right are a few of the corresponding 2D scattering patterns. Dry sample described in the Experimental Section contains a small amount of residual water. The sample (Ex117asr) dried under vacuum for $\sim 3$ days at around $95^{\circ} \mathrm{C}$ showed dark brown color and no ionic peak.

suggests an increase of the interionic domain $\left(L_{\text {ion }}\right)$ distance. The other features of the profile, including the slope of -1 at low $Q$ region and the anisotropy in the 2D scattering pattern, do not change with sorption time (i.e., regardless of water content).

Sorption Kinetics. The sorption kinetics at constant RH are shown in Figure 8 for the pretreated and as-received membranes. The corresponding 2D scattering patterns of the Ex112cln equilibrated at each RH (from $20 \%$ to $95 \%$ with a $15 \% \mathrm{RH}$ interval) are shown in the figure above the circularly averaged profiles.

The sorption kinetics show that $\{\mathrm{d} \Sigma / \mathrm{d} \Omega\}(Q)$ increases rapidly at early sorption times and then levels off upon reaching equilibrium at each RH for both Ex112cln and Ex112asr. Reaching equilibrium at low RH takes less time than at high $\mathrm{RH}$. The weak 2D patterns become more intense as RH increases keeping the original anisotropic scattering shape. Again, this result confirms that the anisotropic structure of perfluorinated membranes does not change with the amount of absorbed water. Correlations among $\lambda$, mass uptake, and total cross section of the ionic peak with vapor pressure $\left(P / P^{\circ}\right)$ at equilibrium are shown in Figure 9.

Assuming $\lambda \approx 0$ at $P / P^{\circ}=0$, the following fitting was obtained as a function of $P / P^{\circ}(=u)$

$$
\begin{aligned}
\lambda= & -0.05( \pm 0.25)+11.12( \pm 2.40) u+ \\
& 19.25( \pm 6.25) u^{2}+20.15( \pm 4.33) u^{3} \quad \text { for Ex112cln }
\end{aligned}
$$

and

$$
\begin{array}{r}
\lambda=-0.026( \pm 0.10)+3.18( \pm 0.95) u+7.03( \pm 2.47) u^{2}+ \\
11.34( \pm 1.71) u^{3} \text { for Ex112asr }(4)
\end{array}
$$

which allows us to estimate the number of water molecules per sulfonic acid group as a function of relative vapor pressure of water. Ex112cln shows higher mass uptake than Ex112asr. The reason may be the presence of organic impurities (as shown in Figure 1 of Ex112asr) that block the water vapor channels, cation impurity, or isolated ionic domain (see Figure 6b). Pretreatment may open the closed (or isolated) domain so that water flows through the channel. Jalani and Datta showed a
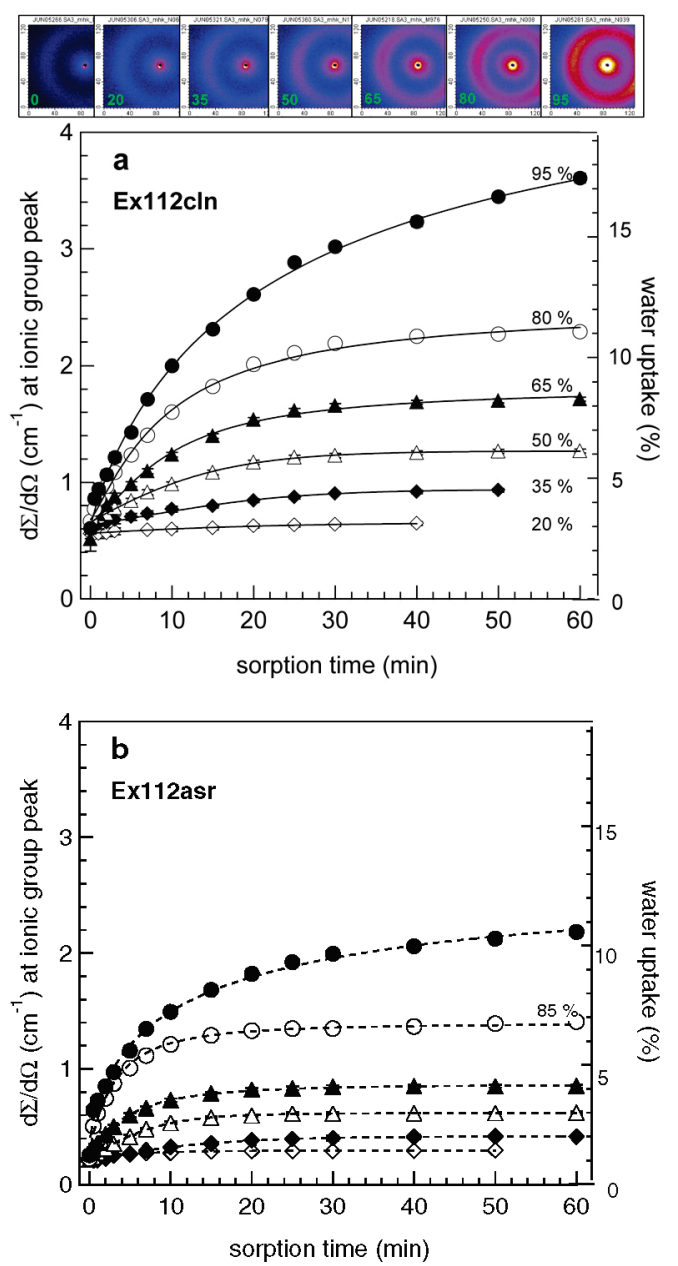

Figure 8. Correlation of the cross section, $\{\mathrm{d} \Sigma / \mathrm{d} \Omega\}(Q)$, at the ionic domain peak position with mass uptake of water vapor, sorption time, at constant relative humidity for pretreated Ex112cln (a) and as-received Ex112asr (b). The curves are labeled by the RH values which ranged from $20 \%$ to $95 \%$ in both cases. The 2D patterns correspond to the last data point (i.e., equilibrium) at each indicated RH of Ex112cln.

decrease of water uptake with increasing size of the cations and understood it to be due to a reduction of ionic hydration capacity. ${ }^{10}$ The mass uptake of both membranes increases slowly with $P / P^{\circ}$ up to $65 \%$, but then increases more steeply. The general sorption tendency of Ex112cln (stack of six pieces) is similar to the published results for a pretreated membrane (N117) that corresponds to our $183 \mu \mathrm{m}$ thick sample; ${ }^{3,10}$ the $\lambda$ values are different from each other.

It is difficult to explain the differences between our data obtained from iVSANS and that in the literature because of differences in the experimental methods used to obtain $\lambda$ and differences in prehistroy (i.e., pretreatment condition), sample thickness, and membrane processing method (extrusion and cast). For example, Slade et al. ${ }^{6}$ showed that thick membranes have higher $\lambda$ values than thin ones in the membranes immersed in bulk water, although absolute $\lambda$ between water vapor and bulk water cannot be compared due to Schroeder's paradox. ${ }^{3,58,59}$ Usually, the $\lambda$ from immersion in bulk water has a higher value. Other possible reason may be due to different sample preparation condition. We used a sample pretreatment of $80{ }^{\circ} \mathrm{C}$, while Zawodzinski et al. ${ }^{3}$ used boiling water and Kreuer $^{4}$ did not mention whether the membrane was pretreated. Higher temperature is expected to affect the structure of the membrane. We point out that our sorption isotherm does not include the water accumulated on the membrane surface but reflects only 

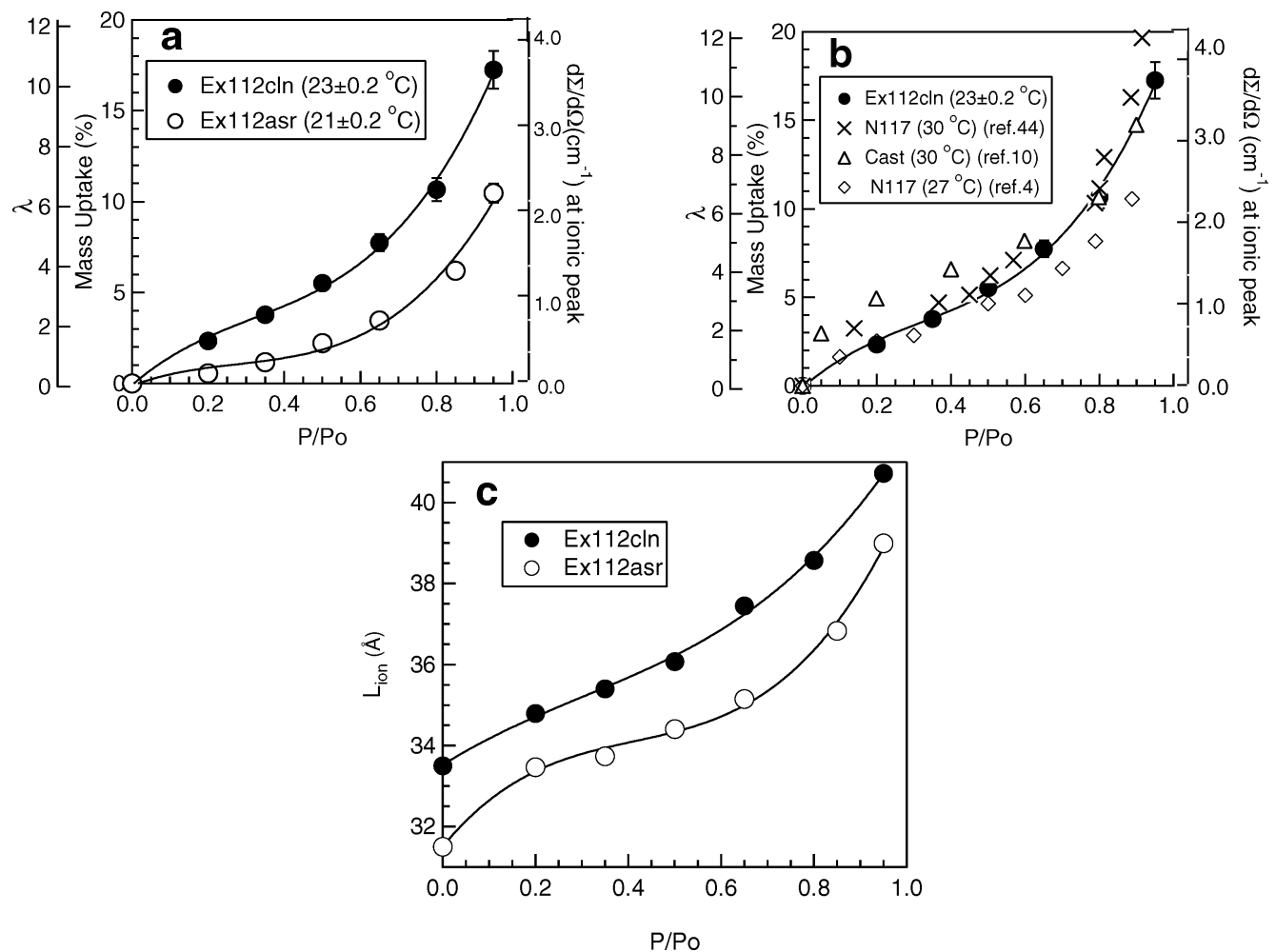

Figure 9. Plots $(\mathrm{a}$ and $\mathrm{b})$ of the total cross section $(\mathrm{d} \Sigma / \mathrm{d} \Omega)$ of ionic peak as a function of mass uptake $(\%)$, number $\left(\lambda=n_{\mathrm{H}_{2} \mathrm{O}} / n_{\mathrm{SO}_{3} \mathrm{H}}\right)$ of water molecules per sulfonic acid group, and relative vapor pressure, $\left\{P / P^{\circ}\right\}(\times 100=\mathrm{RH})$ of water (a) determined from iVSANS. Mass uptake was obtained from the calibration plot (Figure 3 ) and is converted to $\lambda$ with eq 1 . Our $\lambda$ values are compared with those $(E W=1100)$ of refs 44,10 , and 4 in (b). The membranes of refs 44 and 10 were pretreated. The dependence of inter ionic domain distance $\left(L_{\text {ion }}\right)$ with relative vapor pressure $\left(P / P^{\circ}\right)$ is shown in $(\mathrm{c})$

the amount of water inside the membrane (i.e., in the ionic domain) because only the water which penetrated into the membrane (i.e., ionic domain) causes the neutron contrast (see eq 2). We believe that our sorption isotherm truly represents the structure-based sorption isotherm.

Figure 10 shows the $L_{\text {ion }}$ expansion with sorption time. The trend is the same with the increase of cross section shown in Figure 8. Peak analysis (peak position, peak intensity, and full width at half-maximum (fwhm)) was done by fitting with a Lorentzian function.

Relation between Interionic Domain $\left(\boldsymbol{L}_{\mathrm{ion}}\right)$ and Water Uptake. Figure 11 shows the relationship between $L_{\text {ion }}$ and $\phi_{v}$ (fractional volume gain) of absorbed water in Ex112asr (Figure 11A) and Ex112cln (Figure 11B). The value of $\phi_{v}$ was converted from the mass uptake $(w)$ as described in the Experimental Section on water content. The data include all $L_{\text {ion }}$ measured in equilibrium (closed symbol) and nonequilibrium (open symbol) during sorption. The equilibrium and nonequilibrium measurements of $L_{\text {ion }}$ at each RH show the same trends with sorption time. As-received membrane (Figure 11A) shows a linear relationship between $L_{\mathrm{ion}}$ and $\phi_{v}$ beyond the first data point (i.e., $L_{\text {ion }}$ of dry sample) although it does show a curvature when the first data point (dry sample) is included.

Unlike the as-received membrane, the pretreated membrane (Figure 11B), Ex112cln, shows a weak curvature in the increase of $L_{\text {ion }}$ with the fractional volume gain of water. The slope change in the curvature may indicate the transition of the structures with the water content based on the relationship between power law exponent $(p=1,1 / 2$, and $1 / 3$ for lamellae, cylinder, and sphere) and $\phi_{v}$. However, such a transition is not consistent with the fact that iVSANS profiles (Figure 7) exhibit the constant slope of $\approx-1$, which apparently represents a local cylindrical shape of the ionic domain at low- $Q$ region during the sorption.
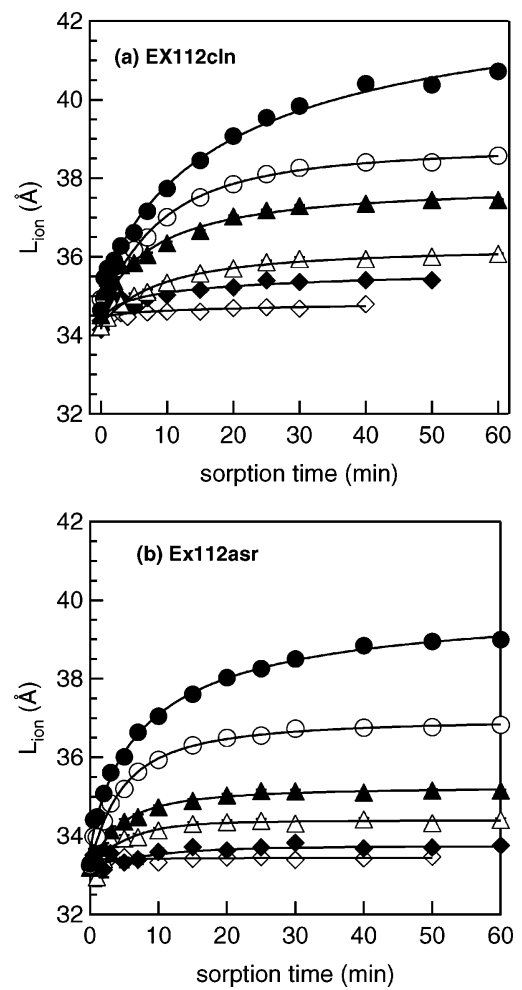

Figure 10. $L_{\text {ion }}\left(=2 \pi / Q_{\text {ion }}\right)$ vs sorption time of pretreated $(\operatorname{Ex} 112 \mathrm{cln})$ and as-received (Ex112asr). The symbols are identical to those of Figure 8. Error bars are within the symbols. The lines are a guide to the eye.

The difference in the slope (i.e., curvature) may be related to the difference in water distribution in the ionic domain at low and high humidity. The water distribution may be related to the uniformity of the aggregation of the sulfonic acids group, 

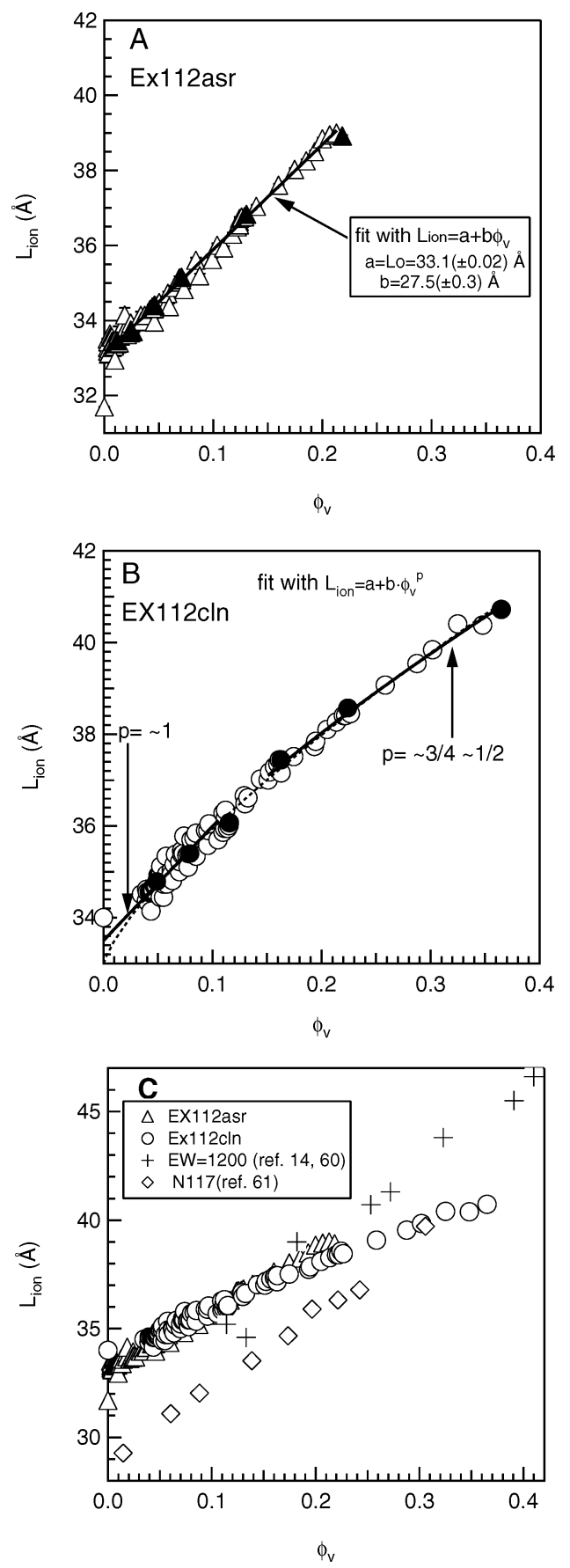

Figure 11. $L_{\text {ion }}$ vs $\phi_{v}$ (fractional volume gain) of (A) as-received (Ex112asr), and (B) pretreated (EX112cln) membrane under in situ water vapor sorption. Linear (A) and power law (B) fittings were done without constraints. The thin dotted line in (B) is a fit for the entire $Q$ range. Closed symbols in (A) and (B) indicate data obtained at the equilibrium at each RH (on the order of 20, 35, 50, 65, 85 (Ex112asr), or $80(E x 112 \mathrm{cln}), 95 \%$ as $\phi_{\nu}$ increases. Comparison with literature data (obtained from $\mathrm{EW}=1200$ (thickness is not known) and two data set of the $\mathrm{H}^{+}$and $\mathrm{Li}^{+}$form [refs 14 and 60] and $\mathrm{N} 117$ ( $\mathrm{H}^{+}$form) [ref 61]) of the membranes wet with bulk water $(\mathrm{C})$. The samples from the literature were conditioned in boiling water.

the variation of the ionic domain channel diameter, the effect of some hydrophobic wall that may partly consist of the water flow channel, and the tortuosity of the channel (schematic is shown in Figure 6b). If elastic force in the matrix responds nonuniformly during sorption, it may affect the $L_{\text {ion }}$ and the slope and intercept of Figure 11.

The difference in the expansion of $L_{\text {ion }}$ between Ex112cln and Ex112asr implies again that pretreatment affects the sorption
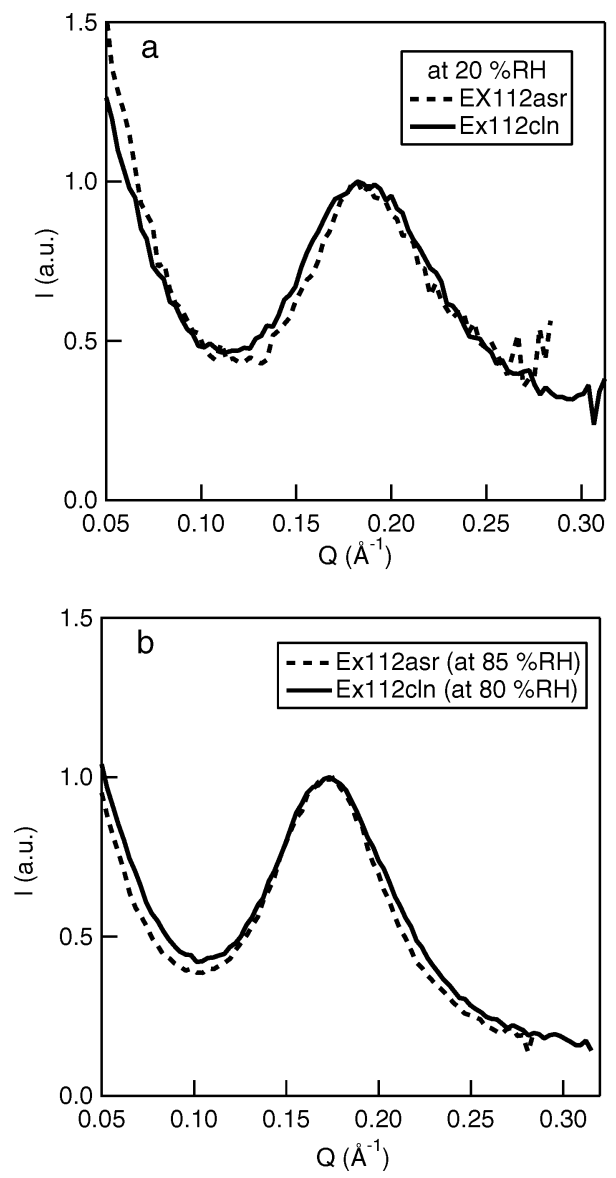

Figure 12. Ionic peak profiles of Ex $112 \mathrm{cln}$ and Ex112asr at 20\% RH and $80-85 \% \mathrm{RH}$. The peak heights and positions were matched to focus attention on the peak shape.

behavior despite the careful pretreatment of the as-received membrane at a temperature (i.e., $80^{\circ} \mathrm{C}$ ) lower than boiling water $^{3}$ (see Experimental Section). When all the data are plot together, the $L_{\text {ion }}$ of the as-received (Ex112asr) is well superimposed to the extrapolation of the EX112cln (Figure 11c). The differences with the literature data (Gierke et al. ${ }^{14}$ and Young et al. ${ }^{61}$ ) may be due to differences in sample prehistory, in wetting method between vapor and bulk water, or in sample thickness and difference in EW.

Fwhm and Porod's Region of Ionic Peak. It is of interest to know whether the peak width of the ionic domains can also show the difference between Ex112asr and Ex112cln and the change with sorption time. The slight differences in the structure and irregularity are expected to appear in the peak width of ionic domain. The peak width of Ex112cln indeed is slightly larger than the as-received Ex112asr (Figure 12), suggesting that the former has a somewhat broader distribution in structure.

The results of mass uptake, expansion of $L_{\mathrm{ion}}$, and fwhm demonstrate that the pretreatment causes minor differences in structure. The membranes with low water content show an asymmetric profile, which becomes more symmetric as water content increases (see Figure 13a). The slope on the high $Q$ side becomes steeper, from slope $\approx-3.4$ (dry) to slope $\approx-5.5$ (95\% equilibrium) for Ex112asr and slope $\approx-5.0(95 \%$ equilibrium) for Ex112cln, with sorption time. The plot of fwhm vs fractional volume gain is shown in Figure 13b.

The fwhm was estimated by fitting with a Lorentzian function. Errors due to asymmetry of the peak profiles are included in the error bars. The fwhm of Ex112cln decreases slightly by as much as $\Delta \mathrm{fwhm} / \mathrm{fwhm} \approx 14 \pm 3 \%$ as the fractional volume 

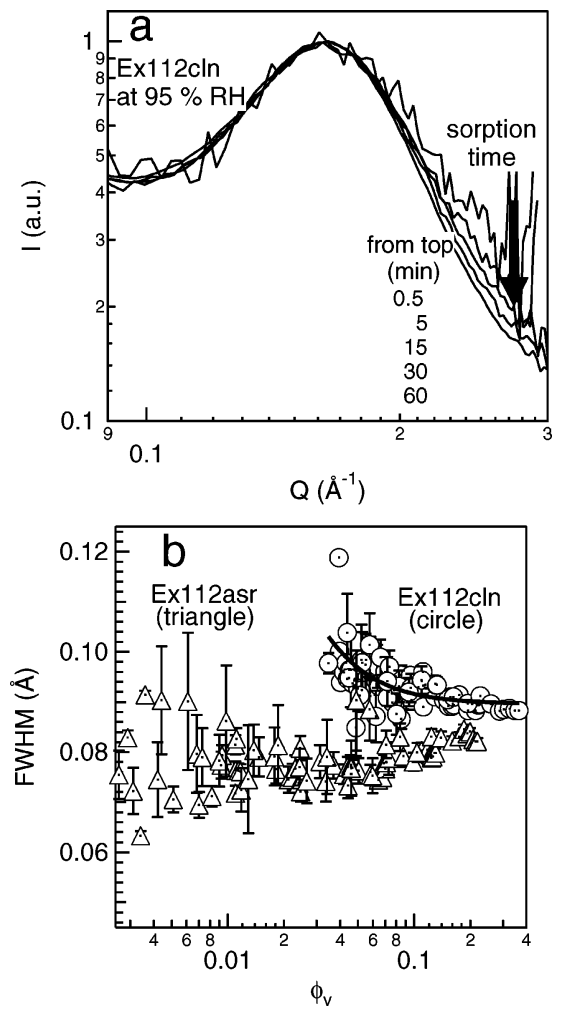

Figure 13. Normalized peak profile (a) of EX112cln with sorption time (the peak positions of the individual scans have been matched for comparison) and fwhm (b) with fractional volume gain of Ex112asr and Ex112cln. Solid line in (b) is a guide for the eye.

gain increases. The data for Ex112asr have substantial scatter but at least show the fwhm does not increase with a fractional volume gain. The decrease of fwhm with increasing fractional volume gain may be due to change in chain mobility and/or minimization of the interfacial energy between ionic domain and matrix during sorption. The pretreated Ex112cln at $80{ }^{\circ} \mathrm{C}$ shows a larger fwhm of the ionic peak than the as-received, demonstrating that the pretreatment at this temperature does affect the chain conformation.

Contrary to our expectation, this result implies that water molecules accumulated in the membrane contribute to a better organized ionic domain structure (i.e, ionic peak becomes narrow) rather than disrupting the structure of membrane (i.e., the peak becomes broad), although the exact structure is not known.

Diffusion Coefficient. Proton transfer in fuel cell membranes such as NAFION depends on the water content in the membrane. One of the advantages of in-situ vapor sorption SANS (iVSANS) is that it allows us to estimate the diffusion coefficient of the vapor. A diffusion coefficient $\left(D, \mathrm{~cm}^{2} / \mathrm{s}\right)$ is defined according to Fick's second law

$$
\frac{\partial C}{\partial t}=D \frac{\partial^{2} C}{\partial x^{2}}
$$

assuming (i) diffusion occurs in one direction (i.e., membrane thickness direction), (ii) $D$ is independent of concentration $(C)$, and (iii) tortuosity of water vapor flow channel (i.e., ionic domain) is not considered. The first two assumptions require that the entire surface (not a point or line) of one side (i.e., $x=$ $L=0)$ of the membrane must reach the target concentration ( $C$ $=C_{1}$ ) immediately and homogeneously before the vapor penetrates into the membrane and then be constant over time, $t$ (Figure 14). The response time of the in-situ vapor sorption

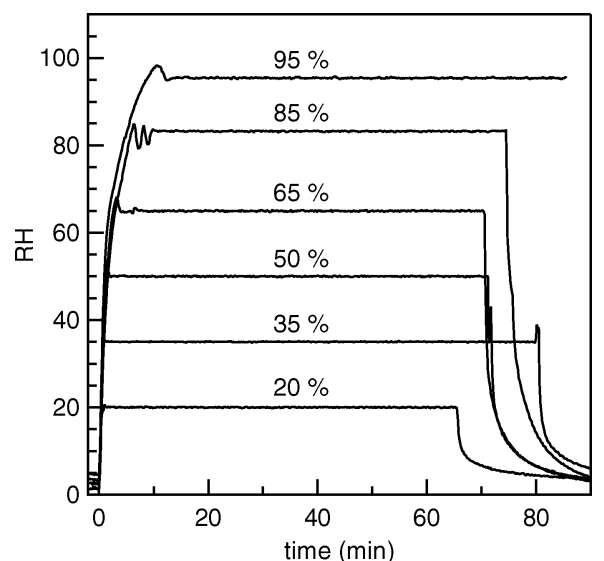

Figure 14. Stability and response time of the relative humidity in the iVSANS cell with six layers of Ex112asr at $21{ }^{\circ} \mathrm{C}$.

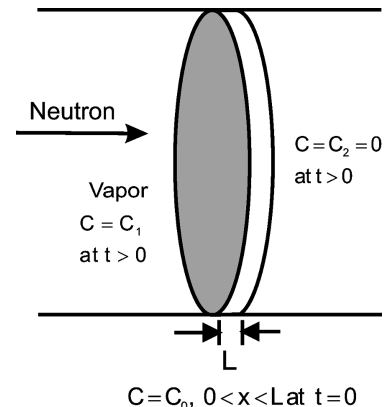

Figure 15. Schematics of boundary condition around membrane in the iVSANS sample cell at initial stage.

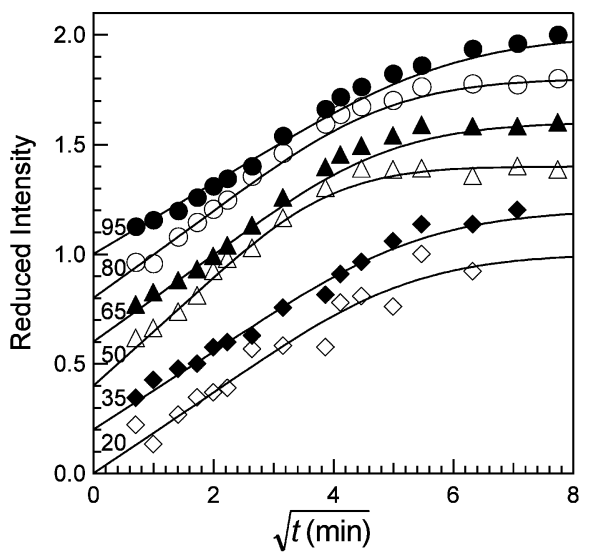

Figure 16. Reduced intensity against $\sqrt{t}$ (unit: $\min ^{1 / 2}$ ) of Ex112cln for RH in a range of $20-95 \%$. For clarity, the data for each RH has been shifted by $\approx 0.2$ from the preceding data set.

cell to reach to the target vapor pressure depends on the relative humidity and the ability of the membrane to absorb the vapor. Once the target RH is reached, the RH becomes stable.

Homogeneous distribution of the vapor in the cell was demonstrated elsewhere. ${ }^{41}$ The membrane is loaded in the insitu vapor sorption cell to satisfy the boundary condition (see Figure 15).

The analytical solution of eq 5 is given by ${ }^{62}$

$$
\frac{M_{t}}{M_{\infty}} \cong 1-\frac{8}{\pi^{2}} \sum_{n=0}^{\infty} \frac{1}{(2 n+1)^{2}} \exp \left(-\frac{D(2 n+1)^{2} \pi^{2} t}{L^{2}}\right)
$$

where $M_{t}$ and $M_{\infty}$ are the amount of mass uptake at time $t$ and equilibrated time $t=\infty$. $L$ is the membrane thickness. Equation 
Table 3. Comparison of Diffusion Coefficients ${ }^{a}$

\begin{tabular}{|c|c|c|}
\hline$D, \mathrm{~cm} / \mathrm{s}$ & method & ref \\
\hline$\sim(7-10) \times 10^{-7}$ & EW1100 $(0.178 \mathrm{~mm})$ water vapor and liquid, pluse-field gradient spin echo, $30^{\circ} \mathrm{C}$ & 3 \\
\hline$(0.25-4.3) \times 10^{-7}$ & EW1100 $(0.178 \mathrm{~mm})$ water vapor soprtion (gravimetry) & 7 \\
\hline & liquid water uptake $\left(1.3 \mathrm{~mm}\right.$, gravimetry, $\left.28^{\circ} \mathrm{C}\right)$ & 8 \\
\hline $2.3 \times 10^{-6}$ & EW1155 & \\
\hline $2.6 \times 10^{-6}$ & EW1365 & \\
\hline$(1.2-1.8) \times 10^{-7}$ & vapor uptake (gravimetry) & 9 \\
\hline & EW1100 $(0.178 \mathrm{~mm}),\left(\right.$ gravimetry at $\left.60^{\circ} \mathrm{C}\right)$ & 9 \\
\hline $4.87 \times 10^{-8}$ & water vapor uptake of the membrane saturated with methanol & \\
\hline $1.87 \times 10^{-7}$ & mixed vapor uptake of methanol/water (1:1 molar ratio) & \\
\hline$(0.5-1.2) \times 10^{-7}$ & $\begin{array}{l}\text { isotope }\left(\mathrm{H}_{2} \mathrm{O} / \mathrm{D}_{2} \mathrm{O}\right) \text { vapor tracing with far-IR spectroscopy (NAFION type and } \\
\text { temperature: unknown) }\end{array}$ & 11 \\
\hline$(0.025-6) \times 10^{-7}$ & $\begin{array}{l}\text { bulk water and vapor soprtion (gravimetry at } 23^{\circ} \mathrm{C} \text { ); various EW, ion form, } \\
\text { thckness, and sample shape (measured in the vol fraction of water of } 2-50 \% \text { ) }\end{array}$ & 64 \\
\hline & EW1100 $(0.051 \mathrm{~mm})$, iVSANS and gravimetry & \\
\hline $\begin{array}{l}2.417 \times 10^{-7}-1.41 \times 10^{-7} \\
1.267 \times 10^{-7}-9.167 \times 10^{-8}\end{array}$ & $\begin{array}{l}\text { as-received (measured at } 21^{\circ} \mathrm{C} \text { ) } \\
\left.\text { pretreated (measured at } 23^{\circ} \mathrm{C}\right)\end{array}$ & $\begin{array}{l}\text { this work } \\
\text { this work }\end{array}$ \\
\hline
\end{tabular}

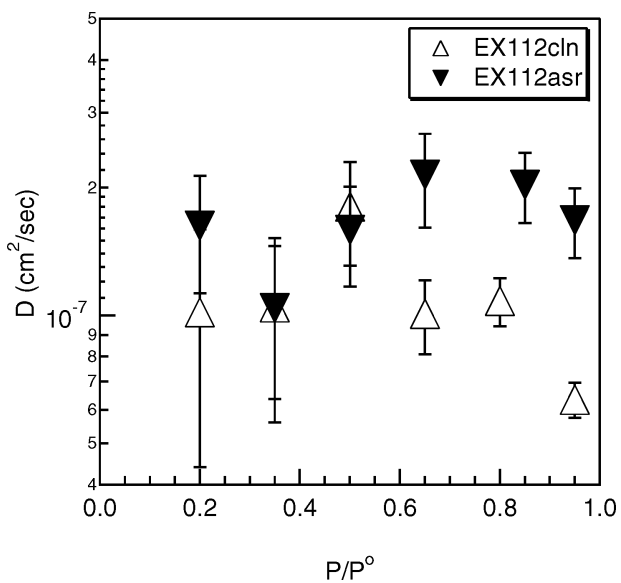

Figure 17. Diffusion coefficient with relative water vapor pressure for Ex112asr and Ex112cln.

6 is simplified for an initial stage (i.e., less than $50 \%$ mass uptake) of sorption

$$
\frac{M_{t}}{M_{\infty}} \cong \frac{4}{L} \sqrt{\frac{D t}{\pi}}
$$

To apply eq 6 or 7 to small-angle scattering data, the mass uptake ratio is replaced with a reduced intensity as follows:

$$
\frac{M_{t}}{M_{\infty}} \cong \frac{I(q)_{t}-I(q)_{\mathrm{i}}}{I(q)_{\infty}-I(q)_{\mathrm{i}}}
$$

where $I(q)_{t}, I(q)_{\mathrm{i}}$, and $I(q)_{\infty}$ represent total intensity at sorption time $t$, initial time (i.e., dry sample), and equilibrium. $D$ can be estimated from the sorption kinetics (i.e., slope in the plot of the reduced total intensity against a squared time) using eq 6 or 7.

Figure 16 shows sorption kinetics of pretreated membrane (Ex112cln). The calculated values with eq 6 or 7 are superimposed on the reduced intensities. This suggests that the sorption kinetics apparently show Fickian-like diffusion behavior.

The vapor diffusion coefficient of Ex112asr and Ex112cln is $D \approx 2 \times 10^{-7} \mathrm{~cm}^{2} / \mathrm{s}$ and $D \approx 1 \times 10^{-7} \mathrm{~cm}^{2} / \mathrm{s}$, respectively. $D$ is nearly independent of relative vapor pressure, as shown in Figure 17.

There is a weak indication of a decrease in $D$ at high vapor pressure [comments: $\mathrm{RH} / 100$ is called by different names in different scientific field: activity, relative vapor pressure, chemical potential]. A similar behavior has been observed in the organic vapor diffusion in polydimethylsiloxane. ${ }^{63}$ Zelsmann and Pineri ${ }^{11}$ reported similar diffusion coefficients, $5.0 \times 10^{-8}$ $1.0 \times 10^{-7} \mathrm{~cm}^{2} / \mathrm{s}$, under isotope sorption using FIR, but their $D$ 's increase up to RH of $50 \%$ and then decrease. They showed that the $D$ with $P / P^{\circ}$ showed various tendencies, depending on the experimental method as well as the difference in diffusion medium (i.e., water vapor sorption and for the bulk liquid). It has been understood the decrease of $D$ at high relative vapor pressure is due to the concentration dependence of the diffusion coefficient ${ }^{63}$ or the fact that the membrane surface exposed to the vapor at high $\mathrm{RH}$ does not reached the vapor equilibrium immediately, ${ }^{11}$ as shown in Figure 14. Meanwhile, Gierke ${ }^{64}$ demonstrated that the diffusion coefficients (from water vapor and bulk water) for NAFION increase with volume fraction and suggested the diffusion constant is concentration-dependent.

Some diffusion coefficients in the literature are listed in Table 3 , including our values. The $D$ obtained from iVSANS is based on the structural evolution of the ionic group/water aggregation with sorption time. This is a different approach from that of the classical gravimetric method. The amount of water molecules condensed on the membrane surface does not affect the scattering intensity increase. The scattering intensity grows only when the water vapor diffuses into the ionic domain and causes the neutron SLD contrast to change. The gravimetric method measures the total amount of water accumulated both on the surface and in the membrane. Thus, the diffusion coefficient obtained by the in-situ vapor sorption/SANS more faithfully reflects the structure-based diffusion coefficient.

\section{Conclusions}

We measured iVSANS for PFSA membranes (as-received and pretreated) with EW $=1100$ as a function of $\mathrm{RH}$ and sorption time. iVSANS is useful (i) for determining the kinetics of water uptake in PFSA membranes because water is selectively absorbed at the ionic sites and (ii) for correlating the sorption behavior with changes in structure. Sorption isotherm and diffusion behavior from iVSANS measurement are truly characteristic of the internal membrane structure because only the water in the ionic domain affects the neutron contrast.

The sorption isotherm of the PFSA membranes shows a strong correlation between $L_{\text {ion }}$ and water uptake. Water goes to the ionic domain, and $L_{\text {ion }}$ increases with sorption time, indicating that the matrix structure changes due to the mobility of the main chains even at room temperature. In addition, the structure of the membranes depends on the membrane processing (melt-extruded and solution casting), prehistory (pretreated at $80{ }^{\circ} \mathrm{C}$ and as-received), and thickness. 
The structure of the ionic domains looks locally cylindrical in shape based on a SANS slope of -1 . The shape of the ionic peak becomes more symmetric and narrower with sorption time (i.e., with increasing water content), without a change in the anisotropy of the scattering.

The degree of crystallinity in the matrix depends on the membrane thickness. The crystalline peak $\left(Q \approx 0.03 \AA^{-1}\right)$ of the melt-extruded membrane was not observed, or was negligible, in the thin membrane (thickness $\leq 50 \mu \mathrm{m}$ ) while the crystalline peak shifted to lower scattering angle (i.e., crystals becomes thicker) with increasing membrane thickness. This is because the cooling rate in the thick melt is slower than or similar to that of a crystallization rate while the rate of cooling in the thin membrane is faster than the crystallization rate.

The prehistory affects the $L_{\text {ion. }}$. The pretreated wet membrane showed a larger $L_{\text {ion }}$ and a broader scattering profile than the as-received one. The SANS slope of -1 in the thin membrane was observed in the $Q$ range of $0.008-0.1 \AA^{-1}$ corresponding to the crystalline peak region of the thick membrane, suggesting the existence of a local cylindrical structure that might be formed by a local packing of the individual chains in the matrix and/or ionic domain. The steep rise at very low $Q$ region $\left(3.0 \times 10^{-5}-\right.$ $10^{-3}$ ) for thick membrane shows the possibility of superstructure originated from clustering of semicrystals.

In addition, the structure is also affected by membrane processing. The melt-extruded membrane exhibited an anisotropic and a better-defined ionic domain as compared to the solution cast one.

Diffusion coefficients of water vapor, based on structure evolution and Fick's second law, are in the range of $1 \times 10^{-7}$ $3 \times 10^{-7} \mathrm{~cm}^{2} / \mathrm{s}$ for both extruded membranes.

Acknowledgment. This work is based on activities supported by NSF (DMR-0454672). We thank Dr. Samuel Trevino (US Army Research Laboratory) and Dr. Paul Butler (NIST) for careful reviewing of the manuscript. Dr. Timothy D. Gierke (DuPont) provided his unpublished data and beneficial comments on the manuscript. The authors Grot and Grot acknowledge support by the Department of Energy under Contract DEFC36-03G013105.

\section{Appendix. Conversion of Mass Uptake to Factional Volume Gain $\phi_{v}$}

The gain of volume on sorption is given by

$$
\phi_{v}=\left(V_{\text {wet }}-V_{\text {dry }}\right) / V_{\text {dry }}
$$

Since volume is related to mass $(m)$ and mass density $(\rho), V=$ $m / \rho$, eq A1 can be expressed as follows:

$\phi_{v}=\left[\left(m_{\text {dry }} / \rho_{\text {dry }}+m_{\mathrm{H}_{2} \mathrm{O}} / \rho_{\mathrm{H}_{2} \mathrm{O}}\right)-\left(m_{\text {dry }} / \rho_{\text {dry }}\right)\right] /\left(m_{\text {dry }} / \rho_{\text {dry }}\right)$

Equation A2 can be simplified for $\rho_{\mathrm{H}_{2} \mathrm{O}}=1 \mathrm{~g} / \mathrm{cm}^{3}$

$$
\phi_{v}=\left(\rho_{\text {dry }} / \rho_{\mathrm{H}_{2} \mathrm{O}}\right) m_{\mathrm{H}_{2} \mathrm{O}} / m_{\text {dry }}
$$

where $m_{\mathrm{H}_{2} \mathrm{O}}=m_{\text {wet }}-m_{\text {dry. }}$. From the definition of the mass uptake gain $w\left(=\left(m_{\text {wet }}-m_{\text {dry }}\right) / m_{\text {dry }}\right)$, eq A3 can be expressed as

$$
\phi_{v}=\left(\rho_{\mathrm{dry}} / \rho_{\mathrm{H}_{2} \mathrm{O}}\right) w
$$

\section{References and Notes}

(1) Grot, W. G. Macromol. Symp. 1994, 82, 161

(2) Rieke, P. C.; Vanderborgh, N. E. J. Membr. Sci. 1987, 32, 313.
(3) Zawodzinski, T. A.; Springer, T. E.; Davey, J.; Jestel, R.; Lopez, C.; Valerio, J.; Gottesfeld, S. J. Electrochem. Soc. 1993, 140, 1981.

(4) Kreuer, K. D. Solid State Ionics 1997, 97, 1.

(5) Büchi, F. N.; Scherer, G. G. J. Electrochem. Soc. 2001, 148, A183.

(6) Slade, S.; Campbell, S. A.; Ralph, T. R.; Walsh, F. C. J. Electrochem. Soc. 2002, 149, A1556.

(7) Morris, D. R.; Sun X. J. Appl. Polym. Sci. 1993, 50, 1445.

(8) Yeo, S. C.; Eisenberg, A. J. Appl. Polym. Sci. 1977, 21, 875.

(9) Gates, C. M.; Newman, J. AIChE J. 2000, 46, 2076.

(10) Jalani, N. H.; Datta, R. J. Membr. Sci. 2005, 264, 167.

(11) Zelsmann, H. R.; Pineri, M. J. Appl. Polym. Sci. 1990, 41, 1673.

(12) Freger, V.; Korin, E.; Wisniak, J.; Korngold, E.; Ise, M.; Kreuer, K. D. J. Membr. Sci. 1999, 160, 213.

(13) Fujimura, M.; Hashimoto, T.; Kawai, H. Macromolecules 1981, 14, 1309.

(14) Gierke, T. D.; Munn, G. E.; Wilson, F. C. J. Polym. Sci., Part B: Polym. Phys. Ed. 1981, 19, 1687.

(15) Elliot, J. A.; Hanna, S.; Elliott, A. M. S.; Cooley, G. E. Macromolecules 2000, 33, 4161 .

(16) Rubatat, L.; Gebel, G.; Diat, O. Macromolecules 2004, 37, 7772.

(17) Barbi, V.; Funari, S. S.; Gehrke, R.; Scharnagl, N.; Stribeck, N. Polymer 2003, 44, 4853.

(18) McLean, R. S.; Doyle, M.; Sauer, B. B. Macromolecules 2000, 33, 6541.

(19) James, P. J.; Antognozzi, M.; Tamayo, J.; McMaster, T. J.; Newton, J. M.; Miles, M. J. Langmuir 2001, 17, 349.

(20) Pivovar, A. M.; Pivovar, B. S. J. Phys. Chem. B 2005, 109, 785.

(21) Heitner-Wirguin, C. Polymer 1979, 20, 371.

(22) Falk, M. Can. J. Chem. 1980, 58, 1495.

(23) Ludvigsson, M.; Lindgren, J.; Tegenfeldt, J. Electrochim. Acta 2000, 45, 2267.

(24) Wang, Y.; Kawano, Y.; Aubuchon, S. R.; Palmer, R. A. Macromolecules 2003, 36, 1138.

(25) Sivashinsky, N.; Tanny, G. B. J. Appl. Polym. Sci. 1981, 26, 2625.

(26) Chen, Q.; Schmidt-Rohr, K. Macromolecules 2004, 37, 5995.

(27) Takasaki, M.; Kimura, K.; Kawaguchi, K.; Abe, A.; Katagiri, G. Macromolecules 2005, 38, 6031.

(28) Elliott, J. A.; Hanna, S. J. Appl. Crystallogr. 1999, 32, 1069.

(29) Vishnyakov, A.; Neimark, A. V. J. Phys. Chem. B 2001, 105, 7830.

(30) Jang, S. S.; Molinero, V.; Ça'’in, T.; Goddard III, W. A. J. Phys. Chem. B 2004, 108, 3149.

(31) Khalatur, P. G.; Talitskikh, S. K.; Khokhlov, A. R. Macromol. Theory Simul. 2002, 11, 566.

(32) Mauritz, K. A.; Stefanithis, I. D.; Davis, S. V.; Scheetz, R. W.; Pope, R. K.; Wilkes, G. L.; Huang, H. H. J. Polym. Sci., Part B: Polym. Phys. Ed. 1995, 55, 181.

(33) Choi, W. C.; Kim, J. D.; Woo, S. I. J. Power Sources 2001, 96, 411.

(34) Wang, H. T.; Holmberg, B. A.; Huang, L. M.; Wang, Z. B.; Mitra, A.; Norbeck, J. M.; Yan, Y. S. J. Mater. Chem. 2002, 12, 834.

(35) Park, H. S.; Kim, Y. J.; Hong, W. H.; Choi, Y. S.; Lee, H. K. Macromolecules 2005, 38, 2289.

(36) Liu, F. Q.; Yi, B. L.; Xing, D. M.; Yu, J. R.; Zhang, H. M. J. Membr. Sci. 2003, 212, 213.

(37) Heitner-Wirgun, C. J. Membr. Sci. 1996, 120, 1.

(38) Banerjee, S.; Curtin, D. E. J. Fluorine Chem. 2004, 125, 1211.

(39) Mauritz, K. A.; Moore, R. B. Chem. Rev. 2004, 104, 4535.

(40) Kim, M.-H.; Glinka, C. J. J. Appl. Crystallogr. 2005, 32, 734.

(41) Kim, M.-H.; Glinka, C. J.; Carter, R. N. Rev. Sci. Instrum. 2005, 76, 113904.

(42) DuPont Technical Information, NAE302, Nov20002.

(43) Ion Power, LIQUION Product Bulletin, 2003.

(44) Zawodzinski, T. A., Jr.; Neeman, M.; Sillerud, L. O.; Gottesfeld, S. J. Phys. Chem. 1991, 95, 6040.

(45) Glinka, C. J.; Barker, J. G.; Hammouda, B.; Krueger, S.; Moyer, J. J.; Orts, W. J. J. Appl. Crystallogr. 1998, 31, 430.

(46) Huang, T. C.; Toraya, H.; Blanton, T. N.; Wu, Y. J. Appl. Crystallogr. 1993, 26, 180.

(47) Barker, J. G.; Glinka, C. J.; Moyer, J. J.; Kim, M.-H.; Drews, A.; Agamalian, R. M. J. Appl. Crystallogr. 2005, 38, 1004.

(48) Unpublished data.

(49) Loppinet, B.; Gebel, G.; Williams, C. E. J. Phys. Chem. B 1997, 101, 1884.

(50) Rubatat, L.; Rollet, A. L.; Gebel, G.; Diat, O. Macromolecules 2002, 35,4050 .

(51) Martin, J. E.; Hurd, A. J. J. Appl. Crystallogr. 1987, 20, 61.

(52) Chan, J. W. J. Chem. Phys. 1965, 42, 93.

(53) Berk, N. F. Phys. Rev. Lett. 1989, 58, 2718.

(54) Flory, P. J. J. Chem. Phys. 1949, 17, 223.

(55) Kim, M.-H.; Phillips, P. J.; Lin. J. S. J. Polym. Sci., Part B: Polym. Phys. 2000, 38, 154.

(56) Starkweather, H. W. Macromolecules 1982, 15, 320. 
(57) Van der Heijden, P. C.; Rubatat, R.; Diat, O. Macromolecules 2004, $37,5327$.

(58) Schroeder, P. Z. Phys. Chem. 1903, 45, 75.

(59) Choi, P. H.; Datta, R. J. Electrochem. Soc. 2003, 150, E601.

(60) Litt, M. H. Polym. Prepr. (Am. Chem. Soc., Div. Polym. Chem.) 1997, $38,80$.

(61) Young, S. K.; Trevino, S. F.; Tan, N. C. B. J. Polym. Sci., Part B: Polym. Phys. 2002, 40, 387.

(62) Crank, J. The Mathematics of Diffusion, 2nd ed.; Oxford University Press: New York, 1975.

(63) Dixon-Garrett, S. V.; Nagai, K.; Freeman, B. D. J. Polym. Sci., Part B: Polym. Phys. 2000, 38, 1461.
(64) Gierke, T. D. Unpublished data. Apparent diffusion coefficient is given by $D=1.45 \times 10^{-6}(\mathrm{vol} \mathrm{fr})^{1.55}$, where vol fr is the volume fractions of water at the equilibrium point.

(65) Certain commercial equipment, instruments, or materials are identified in this paper to foster understanding. Such identification does not imply recommendation or endorsement by the National Institute of Standards and Technology, nor does it imply that the materials or equipment identified are necessarily the best available for the purpose.

(66) NAFION is a Registered Trademark \& E.I. Dupont deNemour's and Company and is used under License by Ion Power Inc.

MA060576U 